\title{
Tutorial Review
}

\section{X-ray Mapping in Electron-Beam Instruments}

\author{
John J. Friel ${ }^{1}$ and Charles E. Lyman ${ }^{2, *}$ \\ ${ }^{1}$ Princeton Gamma Tech, C/N 863, Princeton, NJ 08542, USA \\ ${ }^{2}$ Department of Materials Science and Engineering, Lehigh University, 5 East Packer Avenue, Bethlehem, PA 18015, USA
}

\begin{abstract}
This review traces the development of X-ray mapping from its beginning 50 years ago through current analysis procedures that can reveal otherwise obscure elemental distributions and associations. X-ray mapping or compositional imaging of elemental distributions is one of the major capabilities of electron beam microanalysis because it frees the operator from the necessity of making decisions about which image features contain elements of interest. Elements in unexpected locations, or in unexpected association with other elements, may be found easily without operator bias as to where to locate the electron probe for data collection. $\mathrm{X}$-ray mapping in the SEM or EPMA may be applied to bulk specimens at a spatial resolution of about $1 \mu \mathrm{m}$. $\mathrm{X}$-ray mapping of thin specimens in the TEM or STEM may be accomplished at a spatial resolution ranging from 2 to $100 \mathrm{~nm}$, depending on specimen thickness and the microscope. Although mapping has traditionally been considered a qualitative technique, recent developments demonstrate the quantitative capabilities of X-ray mapping techniques. Moreover, the long-desired ability to collect and store an entire spectrum at every pixel is now a reality, and methods for mining these data are rapidly being developed.
\end{abstract}

Key words: X-ray mapping, compositional imaging, X-ray spectrometry, EDS, WDS, concentration-concentration histograms, spectrum imaging, position-tagged spectrometry, principal component analysis, multivariate statistical analysis

\section{INTRODUCTION}

Production of images showing elemental distributions on a fine scale is an important contribution of electron microscopy to scientific investigations. X-ray maps are formed by collecting characteristic $\mathrm{X}$ rays from elements in the specimen as a focused electron beam is scanned in a raster across the specimen. In the 50 years since the first compositional image was obtained in an electron-beam instrument (Cosslett \& Duncumb, 1956), there has been extraordinary progress. For the first 25 years, qualitative analog dot maps were used to form X-ray maps of elemental distributions. Computer control of the electron beam and computer storage of digital images dramatically changed X-ray mapping to the point that digital methods are standard in all commercial systems.

This article reviews X-ray mapping in the scanning electron microscope (SEM), the electron probe microanalyzer (EPMA), and the type of analytical transmission electron microscope (AEM) based on the scanning transmission electron microscope (STEM). Electrons are ideal for generating X-ray compositional images because they can be fo-

Received June 24, 2004; accepted November 7, 2005.

${ }^{*}$ Corresponding author. E-mail: charles.lyman@lehigh.edu cused to a small probe, they can be deflected to form a scanned beam raster, and they can excite atoms in the specimen to produce characteristic X-ray signals. All other beams that might be used to excite an element-specific signal suffer from specimen preparation difficulties, poor spatial resolution, or quantification problems. Other compositional imaging methods are compared with electron beam methods in Table 1. Two important analytical parameters are listed in the table for each method: the spatial resolution of analysis and the elemental detection limit, the smallest amount of an element that can be detected in a matrix. For Table 1 these parameters have been estimated for the mapping mode of analysis where the values are about an order of magnitude worse than the ultimate capabilities of each instrument. X-ray mapping remains the most convenient and popular method for producing compositional images.

\section{Analog versus Digital Maps}

\section{Early Work}

Castaing (1951) built the first practical EPMA in which an electron beam excited characteristic $\mathrm{X}$ rays that were detected with an X-ray spectrometer; however, that instru- 
Table 1. X-ray Mapping Methods Compared with Other Methods for Determining the Distribution of Elements in Solids

\begin{tabular}{|c|c|c|c|c|c|c|}
\hline & Method name ${ }^{a}$ & Input beam & $\begin{array}{l}\text { Output } \\
\text { signal }\end{array}$ & $\begin{array}{l}\text { Lateral } \\
\text { resolution }\end{array}$ & $\begin{array}{l}\text { Detection } \\
\text { limit }^{\mathrm{b}}\end{array}$ & Remarks \\
\hline \multirow[t]{3}{*}{ X-ray mapping methods } & SEM/EDS & Electrons & $\mathrm{X}$ rays & $\sim 1 \mu \mathrm{m}^{\mathrm{c}}$ & $1 \mathrm{wt} \%$ & Routine specimen preparation, rapid \\
\hline & EPMA/WDS & Electrons & $\mathrm{X}$ rays & $\sim 1 \mu \mathrm{m}$ & $0.1 \mathrm{wt} \%$ & Quantitative X-ray maps \\
\hline & AEM/EDS & Electrons & $\mathrm{X}$ rays & $\sim 2-5 \mathrm{~nm}$ & $1 \mathrm{wt} \%$ & Normal thickness TEM specimens \\
\hline \multirow[t]{6}{*}{ Other methods } & AEM/PEELS & Electrons & Electrons & $\sim 1 \mathrm{~nm}$ & $0.1 \mathrm{wt} \%$ & Very thin TEM specimens required \\
\hline & SAM/AES & Electrons & Electrons & $\sim 50 \mathrm{~nm}$ & 1 at $\%$ & Surface analysis, depth profiles \\
\hline & SIMS & Ions & Ions & $1 \mu \mathrm{m}$ & $100 \mathrm{ppb}$ & $\begin{array}{l}\text { Depth profiles, best element } \\
\text { sensitivity }\end{array}$ \\
\hline & PIXE & $\mathrm{H}^{+}, \mathrm{He}^{++}$ & $\mathrm{X}$ rays & $2 \mu \mathrm{m}$ & $0.01 \mathrm{wt} \%$ & Analytical sensitivity \\
\hline & Atom probe & $\begin{array}{l}\text { Atom extraction } \\
\text { voltage }\end{array}$ & Ions & Atomic & One atom & Sharp needle specimen required \\
\hline & Micro IR & Infrared light & Infrared light & $10 \mu \mathrm{m}$ & N/A & Molecular spectroscopy \\
\hline
\end{tabular}

aSEM/EDS: scanning electron microscope/energy-dispersive spectrometer. EPMA/WDS: electron probe microanalyzer/wavelength-dispersive spectrometer. AEM/EDS: analytical transmission electron microscope/energy-dispersive spectrometer. AEM/PEELS: analytical transmission electron microscope/parallel collection electron energy loss spectrometer. SAM/AES: Scanning Auger microscope/Auger electron spectrometer. SIMS: secondary ion mass spectrometer. PIXE: proton induced X-ray emission.

${ }^{\mathrm{b}}$ Detection limits for maps have been estimated to be $10 \times$ greater (worse) than single point analysis because of the limited dwell time per pixel.

${ }^{\mathrm{c}}$ For low-voltage SEM/EDS the lateral spatial resolution can be as small as $0.1 \mu \mathrm{m}$.

ment could only analyze one specimen point at a time. Duncumb and Cosslett obtained the first X-ray "dot map" compositional image (Cosslett \& Duncumb, 1956; Duncumb \& Cosslett, 1957) by modifying an EPMA such that the electron beam could be scanned across the specimen surface to generate characteristic X-ray signals as a function of beam position (see Fig. 1). In this first X-ray map, the $\mathrm{Cu} \mathrm{K}_{\alpha}$ and $\mathrm{Ag} \mathrm{L}_{\alpha}$ signals were separated by the energydispersive properties of a gas proportional counter (about $1000 \mathrm{eV}$ energy resolution). Because the detector was placed beneath the specimen and $\mathrm{X}$ rays were collected in transmission, dark lines appeared where X-ray absorption was the greatest. Soon after this initial demonstration, the wavelength-dispersive spectrometer (WDS) was employed to detect $\mathrm{X}$ rays for maps, extending the technique to more general commercial applications (Melford \& Duncumb, 1958). A decade later the energy-dispersive X-ray spectrometer (EDS) became available for X-ray mapping in electronbeam instruments (Fitzgerald et al., 1968).

\section{Analog Dot Maps}

Because EDS and WDS systems can be attached to almost any SEM or EPMA, X-ray analog "dot maps" are possible on all such instruments, even those of old vintage. As the beam scans across the specimen in a continuous raster, a momentary bright flash is registered on the cathode ray tube (CRT) screen when an $\mathrm{X}$ ray enters the spectrometer within a preselected X-ray energy range. These flashes (dots) are captured directly on film by leaving the camera shutter open. The resulting image is one of dots built up on the film, and the relative concentration of the element is inferred by observing the clustering (areal density) of the dots.
For guidelines on the setup of analog dot maps, the reader is referred to Goldstein et al. (1981). Because characteristic $\mathrm{X}$-ray signals from the specimen are much weaker than emitted electron signals, analog X-ray maps are often acquired over several scan rasters (image frames), a process that may take up to an hour or longer for each element. A total of 250,000 counts (dots on the film) is considered the minimum exposure for a high quality dot map (Goldstein et al., 1992). An example of an analog dot map is shown in Figure 2. Although simple to acquire, dot maps have several disadvantages: They must be recorded (photographed) one element at a time upon acquisition, they lack discrete intensity levels, they lack a suitable method for background subtraction, and they are inherently qualitative (Newbury et al., 1990a). These difficulties can be resolved by collecting the X-ray map digitally.

\section{Digital Intensity Maps}

X-ray maps made with early digital mapping software showed only the presence or absence of the selected characteristic $\mathrm{X}$ ray for a digital array of pixels. In some early systems, there was only one intensity level at each pixel (see Fig. 3); however, element-specific phases were much easier to recognize compared with the analog dot map.

In true digital intensity maps the electron beam stops on an image pixel, and the number of counts collected from an element within a specified dwell time is recorded as a numerical value (Chambers, 1981; McCarthy et al., 1981; Newbury et al., 1990a, 1990b). The X-ray background may be subtracted in several ways, and the final image may be displayed at the microscope or stored to be photographed later. Figure 4 is an example of a digital map that clearly 


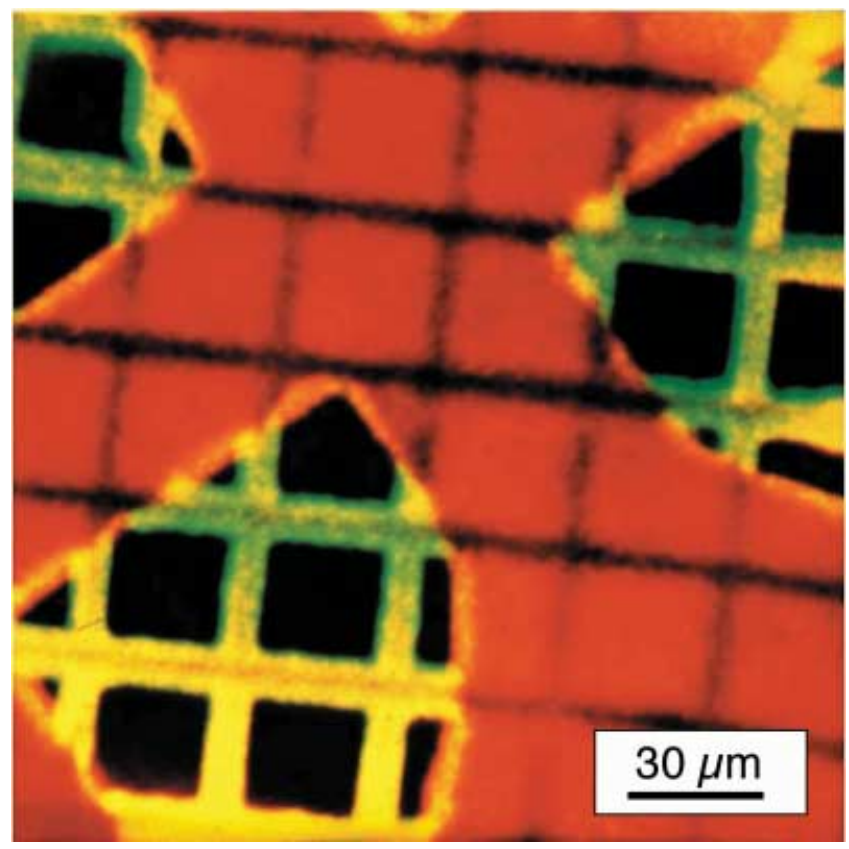

Figure 1. First use of a scanning electron beam instrument to record X-ray maps. The detector was a proportional counter mounted under the specimen. Separate maps were acquired for the $\mathrm{Cu} \mathrm{K}_{\alpha}$ line and the $\mathrm{Ag} \mathrm{L}_{\alpha}$ line. Separate element maps were converted to color and superimposed with red $=\mathrm{Cu}$ and green $=$ Ag. (Courtesy of P. Duncumb.)

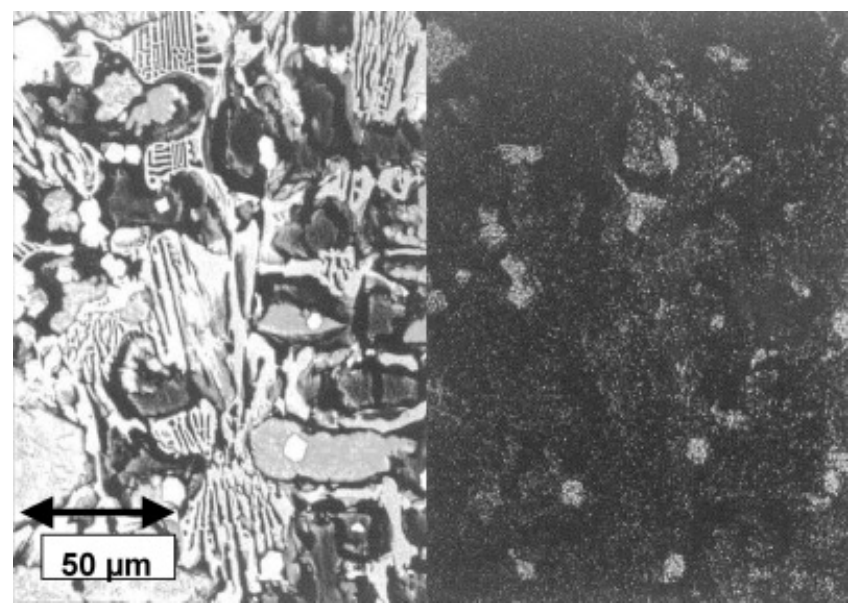

Figure 2. Analog "dot map" of niobium (right) in a tool steel shown with BSE image (left) for comparison. Note the presence of niobium in Nb-carbides.

shows aluminum present in two distinct concentrations (two phases). Digital image processing (Fiori, 1986a) and analysis (Russ, 1990) may be performed on stored maps to reveal stereological information about the specimen such as the volume fraction of a particular phase or chemical compound.
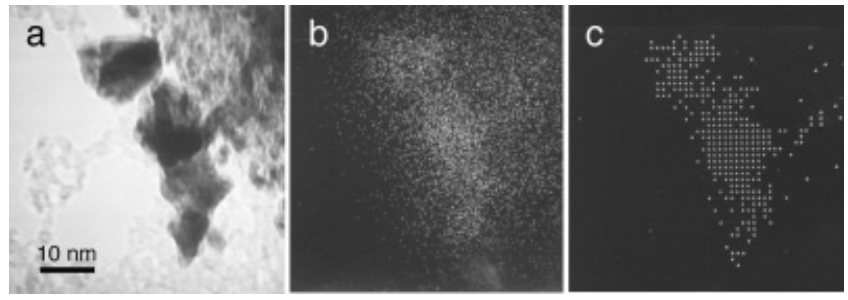

Figure 3. Comparison of analog dot map with digital map of palladium particle on carbon. a: STEM bright-field image of Pd particle. b: Conventional dot map of particle taken with $\mathrm{Pd} \mathrm{L}_{\alpha}$ $\mathrm{X}$ rays. c: Digital map taken with $\mathrm{Pd} \mathrm{L}_{\alpha} \mathrm{X}$ rays of same area after subtracting one count of background X rays (Lyman, 1992). (Courtesy of the Microscopy Society of America.)

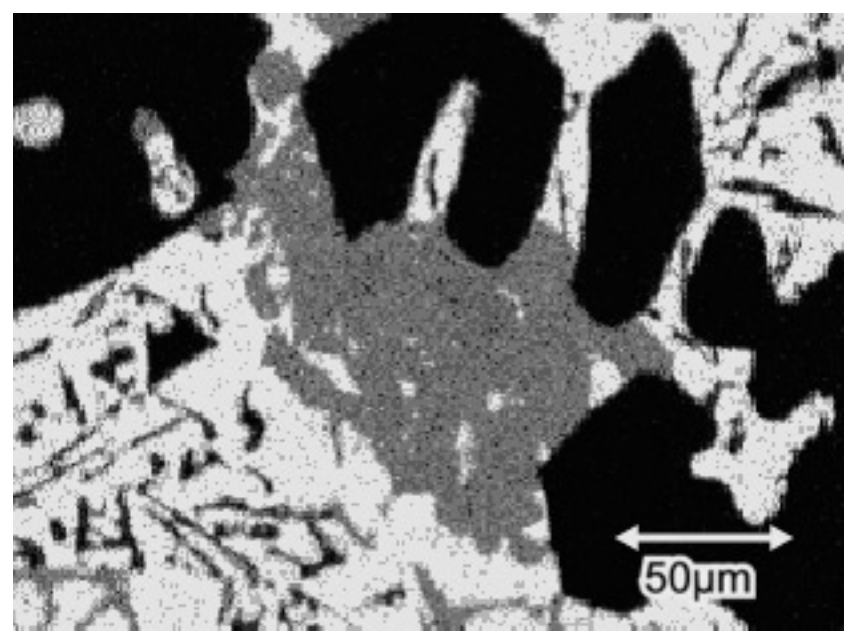

Figure 4. Digital X-ray map of $\mathrm{Al}$ in a corrosion-resistant alloy. Note that the relative $\mathrm{X}$-ray intensity shows $\mathrm{Al}$ at two distinct concentration levels (two phases).

Because of the ability to display and store digital intensity levels and the flexibility of computer processing, digital X-ray map collection has completely displaced the analog method in modern systems (Marinenko et al., 1987; Goldstein et al., 1992). A disadvantage of digital maps, though, is that they are generally collected sequentially. That is, the beam dwells at each pixel for a specified time to collect X-ray counts, and then the beam steps to the next pixel. Usually, the map as a whole is not available until completion, which may take up to an hour or more, and in that time specimen drift, contamination, and electronbeam damage may invalidate the map. One advantage that analog "dot" maps had was that they allowed the user to do a survey scan of an area to check its suitability for collection of longer-term maps. Various schemes for "fast mapping" have been developed to collect digital maps more rapidly, so as to mimic the survey-scan capability of analog maps. 

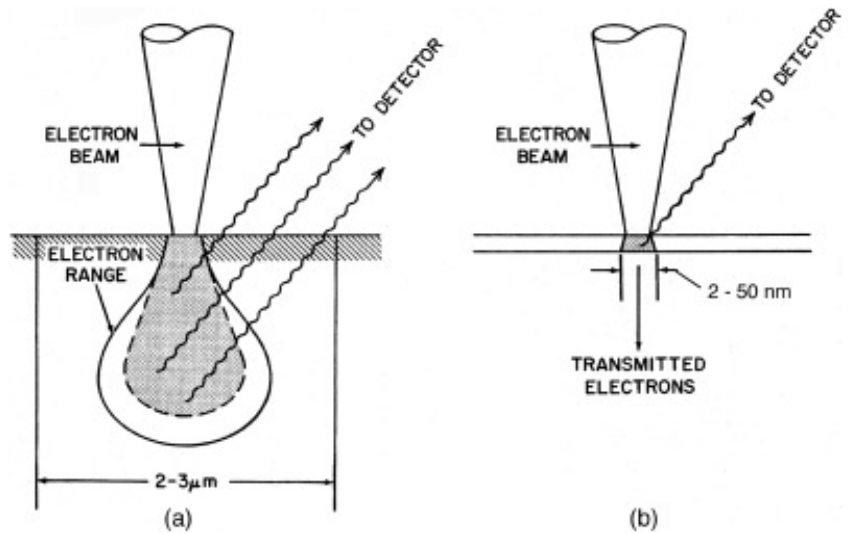

Figure 5. a: X-ray excitation volume for a bulk sample. b: X-ray excitation volume for a thin sample.

\section{INSTRUMENTATION}

This review concentrates only on the instrumentation details related to X-ray mapping. Descriptions of the microscopes and detector systems available can be found in standard textbooks for SEM (Goldstein et al., 2003) and TEM (Williams \& Carter, 1996).

\section{Electron-Beam Instruments}

The SEM and the EPMA are used for generating X-ray maps in bulk specimens. $X$ rays are measured either with an energy-dispersive spectrometer (EDS) or with a wavelengthdispersive spectrometer (WDS). The principal advantage of analyzing flat-polished bulk specimens is the strong X-ray signal that can be generated in the relatively large X-ray excitation volume (Fig. 5a). The main disadvantage of bulk specimens is that the large excitation volume allows only a modest X-ray spatial resolution. For example, an X-ray map from a copper specimen analyzed at $20 \mathrm{keV}$ would have a spatial resolution of about 1-2 $\mu \mathrm{m}$ (Goldstein et al., 2003).

Thin specimens observable in the TEM do not have the large excitation volume beneath the surface (Fig. 5b), and the spatial resolution largely depends on the beam size and the specimen thickness (Williams \& Carter, 1996). For thermionic TEM/STEM instruments, the beam size must be made relatively large $(10-50 \mathrm{~nm})$ to obtain a suitable number of $\mathrm{X}$-ray counts. In systems with a field emission gun (FEG), there is enough current in a 2-nm beam to allow successful analysis of exceedingly thin specimens with 2-5-nm spatial resolution (Lyman, 1986; Williams et al., 2002). However, for all AEMs, beam broadening in thicker specimens (Goldstein et al., 1977; Reed, 1982) will degrade the X-ray spatial resolution up to several times the beam size. The spatial resolution advantage of thin specimen analysis is countered by an enormous loss in generated X-ray signal intensity, as much as a factor of $10^{4}-10^{6}$ times compared to a bulk specimen. To compensate for the loss in X-ray excitation

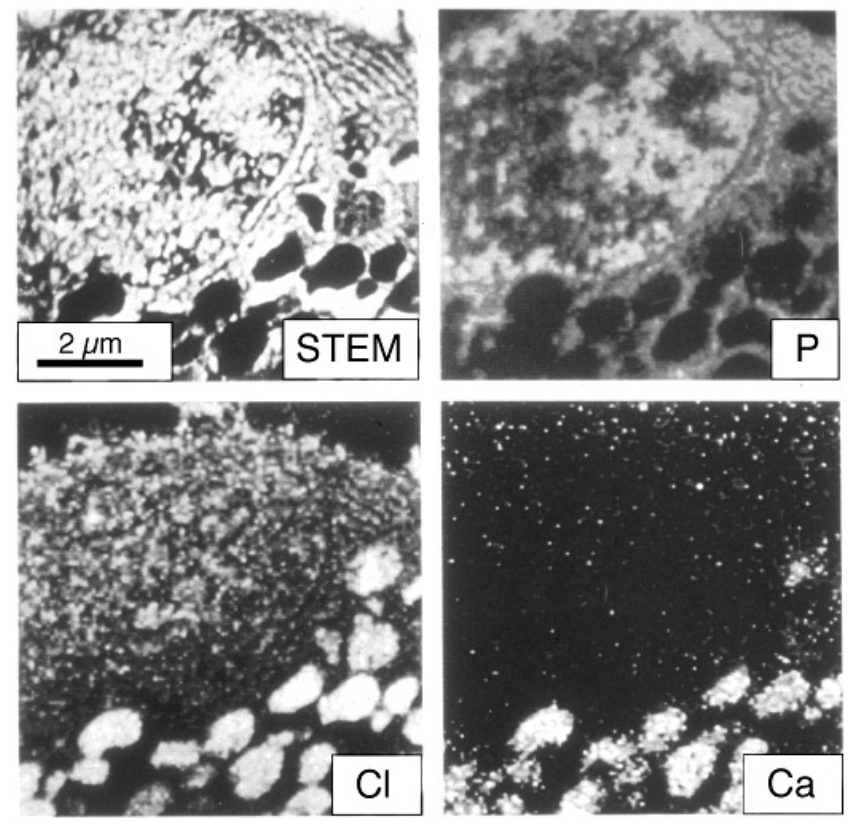

Figure 6. Digital X-ray map of a freeze-dried cryosection of a rat parotid gland showing STEM image and three X-ray maps: phosphorus, chlorine, and calcium. Maps were taken over $12 \mathrm{~h}$ in a tungsten-filament TEM modified for STEM operation. Image width $=10 \mu \mathrm{m}$. (Courtesy of M. Cantino.)

volume, efforts have been made to generate and collect the largest possible X-ray signal in advanced FEG-STEM instruments designed for this purpose (Lyman et al., 1994). In TEMs with conventional thermionic electron sources (e.g., $\mathrm{W}$ or $\mathrm{LaB}_{6}$ ), similar large currents may be obtained by using a large beam size at low image magnification $(5000 \times-$ $15,000 \times)$ and by counting for a relatively long time at each pixel. The latter step may lengthen the map acquisition time from about $1 \mathrm{~h}$ (with an FEG) to $10 \mathrm{~h}$ or more (overnight operation) for a useful map (Wong et al., 1989) as shown in Figure 6.

\section{X-ray Spectrometers}

X-ray maps may be produced with any type of X-ray spectrometer. The key X-ray detector parameters are count rate capability and energy resolution of the $\mathrm{X}$-ray peaks (peak width). The most common X-ray detector is the lithium-drifted silicon $(\mathrm{Si}(\mathrm{Li}))$ EDS detector. Several reviews of EDS instrumentation have appeared (Williams et al., 1995; McCarthy, 1998; Goldstein et al., 2003). All EDS detectors have the advantage of detecting and displaying $\mathrm{X}$ rays over a large energy range, say $0-20 \mathrm{keV}$. Regions of interest (ROIs) or windows can be set up around each analytical peak, and the integrated counts within the window may be used to modulate pixel intensities in a single element map. The spectral energy resolution of an EDS detector decreases as the count rate increases. Typical total 

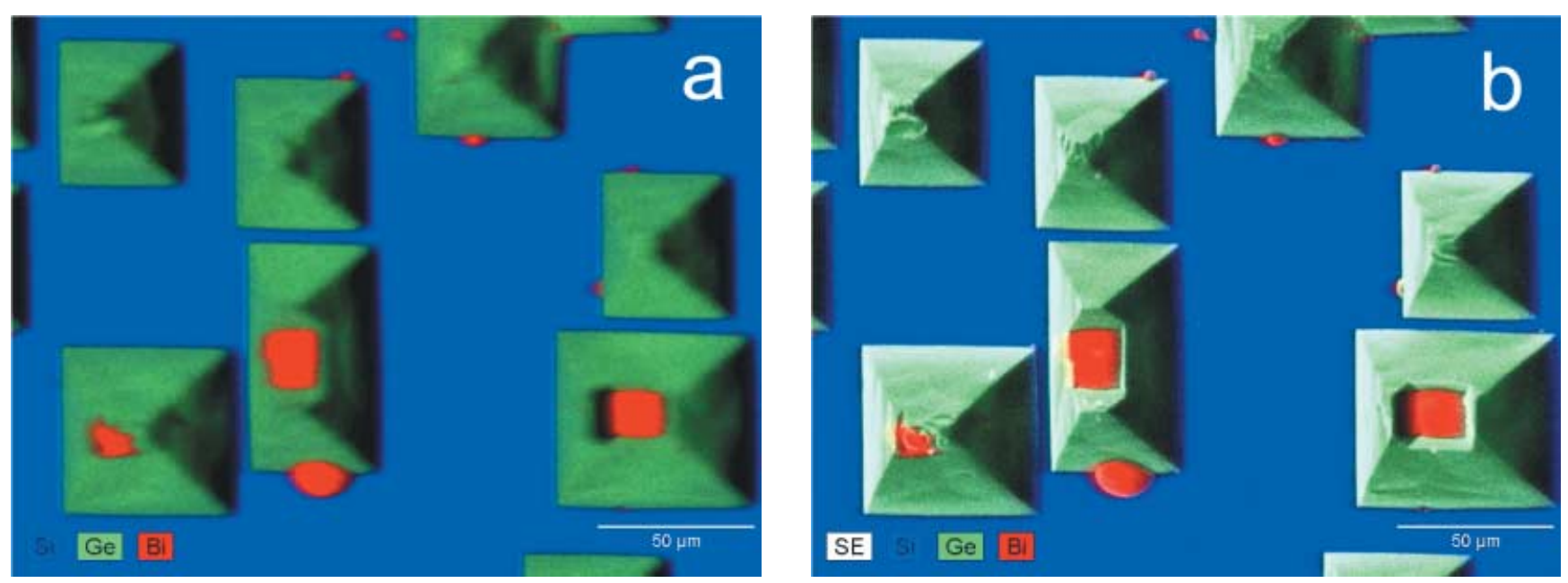

Figure 7. High-count rate map collected with a silicon drift detector. Germanium crystals on a Si substrate with some Bi impurities. X-ray count rate at $15 \mathrm{kV}$ was $140,000 \mathrm{cps}$ at $180 \mathrm{eV}$ energy resolution. Collection time was $12 \mathrm{~min}$. a: X-ray map alone. b: X-ray map with SEM image superimposed. (Courtesy of Röntec, GmbH.)

spectrum count rates are 2000 counts per second at $130 \mathrm{eV}$ energy resolution or $10,000 \mathrm{cps}$ at $180 \mathrm{eV}$ resolution. For mapping purposes, except in the case of severe peak overlaps, energy resolution is less important than count rate, so the spectrometer pulse processing time constant should be set for the fastest counting (shortest time constant) (Statham, 1995). Detectors with larger active areas also produce maps of higher quality. Significantly better maps are obtained with the recently developed silicon drift detector (SDD), which is capable of count rates up to 500,000 cps (Strüder et al., 1999) as shown in Figure 7.

Wavelength-dispersive spectrometers scan a diffracting crystal or grating over a large angular range to separate $\mathrm{X}$ rays by energy (wavelength). Typical WDS spectrometers achieve about $10 \times$ better energy resolution than EDS detectors, but they have lower efficiencies and collection angles. They are capable of high count rates (up to 50,000 cps for a single element) at higher electron beam currents. However, WDS maps are collected one element to a spectrometer. Thus, if more elements are to be mapped than the available WDS spectrometers, the extra maps must be collected by scanning the area additional times. In cases of peak overlaps or trace elements, WDS with its better energy resolution (5-20 eV) produces better maps than EDS (Goldstein et al., 1992). Polycapillary X-ray optics have been used with WDS to increase the X-ray counts collected from the specimen and exploit the count rate advantage of the WDS (Gao et al., 1996).

\section{X-RAy Map Acquisition}

\section{Spatial Resolution}

Spatial resolution in X-ray mapping is determined by the volume of the X-ray excitation region: a region for which beam electrons still have the critical excitation energy $E_{c}$ necessary to generate the characteristic $X$ ray of interest. Thus, the spatial resolution for an X-ray map collected from a flat bulk specimen is approximately the X-ray range, the depth and lateral extent of the volume from which the $\mathrm{X}$ rays emanate. The $\mathrm{X}$-ray range is always smaller than the electron range for a given accelerating voltage and specimen material.

Electron and X-ray ranges may be visualized in Monte Carlo simulations, as shown in Figure 8. Early work on the use of Monte Carlo techniques to simulate electron trajectories was done by various workers (Berger, 1963; Green, 1963; Heinrich et al., 1976; Newbury \& Joy, 1986). Modern implementations of Monte Carlo simulations on personal computers are now widely available (Joy, 1995; Brundle et al., 1996; Hovington et al., 1997). An approximate practical spatial resolution can be calculated from the $\mathrm{X}$-ray range expression of Anderson and Hasler (1966):

$$
R_{x}(\mu \mathrm{m})=\frac{0.064\left(E_{0}^{1.68}-E_{c}^{1.68}\right)}{\rho}
$$

where $E_{0}$ is the electron accelerating voltage and $E_{c}$ is the critical excitation voltage for a particular X-ray line, both in kiloelectron volts. Specimen density is given as $\rho$ in grams per centimeter cubed. Traditional X-ray microanalysis at 20-30 keV produces X-ray ranges of a few micrometers, depending on the material (Fig. 8a).

The spatial resolution of bulk-specimen X-ray maps can be improved by collecting the map at a low accelerating voltage. Equation (1) predicts that submicron X-ray spatial resolution is possible at low voltage; for example, $R_{x}=$ $0.33 \mu \mathrm{m}$ for Si at $5 \mathrm{kV}$ (see Fig. 8b). Most elements can be analyzed with a beam energy of $5 \mathrm{keV}$, and the light elements and first transition series metals can be analyzed even 

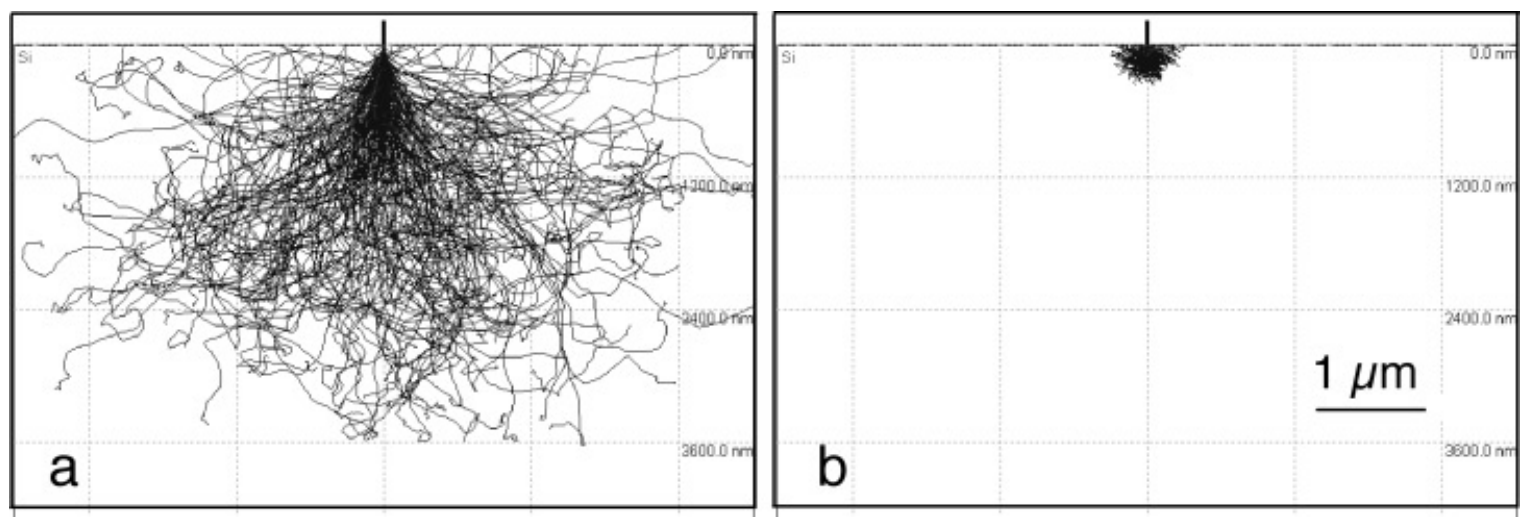

Figure 8. Monte Carlo simulations of electron interaction volumes for $\mathrm{Si}$ at $20 \mathrm{keV}$ (a) and $5 \mathrm{keV}$ (b). Actual X-ray excitation volume is slightly smaller than envelope shown. Size of excitation volume decreases as atomic number increases. Simulations were made with CASINO (Hovington et al., 1997), which is available at http://www.gel. usherbrooke.ca/casino.

at $1.5 \mathrm{keV}$ (Boyes, 2001). However, overlaps of K-lines from light elements with L- and M-lines from heavier elements limit the low-voltage mapping capabilities of conventional EDS systems. Low-voltage EDS is also useful where surface sensitivity is important, such as in mapping of thin films (Kuypers, 2001). Low-voltage imaging and analysis is often possible without a conductive coating to reduce charging, in which case mapping becomes even more surface sensitive (Boyes, 2000).

For thin TEM specimens the spatial resolution of an $\mathrm{X}$-ray map is a function of the accelerating voltage, the electron beam size at the specimen, and the specimen thickness (Goldstein et al., 1977). For metal foil thicknesses used in defect analysis, say $100 \mathrm{~nm}$, the beam broadens by 5-50 nm depending on the specimen atomic number. For instruments with thermionic electron guns, the beam diameter that carries sufficient current $(\sim 1 \mathrm{nA})$ is often about the same size as the broadening. So the X-ray map spatial resolution is typically $10-100 \mathrm{~nm}$ for a metal at $100 \mathrm{keV}$ depending on the specimen and the microscope (Goldstein et al., 1986). For a field-emission STEM, sufficient signal may be obtained with smaller electron beams and from thinner specimens, leading to an X-ray map spatial resolution on the order of $5 \mathrm{~nm}$ at $100 \mathrm{keV}$ (Lyman, 1986) and $2 \mathrm{~nm}$ at $300 \mathrm{keV}$ (Watanabe et al., 1997). Aberrationcorrected STEM instruments operating at 200-300 keV are predicted to produce X-ray maps with subnanometer spatial resolution (Williams et al., 2002).

\section{Map Magnification}

To avoid hollow magnification, X-ray maps should be collected at a magnification where the pixel size approximates the X-ray range given in equation (1). Because the number of pixels in a line of a digital map is selected by the operator, the maximum useful map magnification $M$ can be calculated as follows:

$$
M=\frac{L}{R_{x} N_{p}},
$$

where $L$ is the width of the screen image in one dimension, $R_{x}$ is the X-ray range, and $N_{p}$ is the number of pixels in a line of the image. Variables $L$ and $R_{x}$ must be in the same units. This relationship is illustrated in Table 2. For a polished bulk specimen of copper, the $\mathrm{Cu} \mathrm{K}_{\alpha} \mathrm{X}$-ray map at $20 \mathrm{kV}$ has a spatial resolution (X-ray range) of about 0.8 $\mu \mathrm{m}$ (equation (1)), which equals the pixel size at $1,000 \times$ magnification in a $128 \times 128$ map (Table 2). This means that each discrete analytical point will be sampled without overlapping analysis points and without spaces between points. Because X-ray generation within the interaction volume is not uniform, an oversampling (overscanning) of pixels by a factor of two $\left(2 N_{p}\right.$ pixels $=\mathrm{X}$-ray range $)$ is often used. A map of lower magnification than that given by equation (2), but at the same pixel density (same $N_{p}$ ), leaves gaps on the specimen that are unsampled (underscanning). Though the latter condition may be chosen to save time or

Table 2. Estimated X-ray Map Spatial Resolution Assuming that the Size of the X-ray Excitation Volume (X-ray Range) Equals the Pixel Size and that the Viewing Screen is $10-\mathrm{cm}$ Wide

\begin{tabular}{cccrrr}
\hline & \multicolumn{2}{c}{ SEM $(1$ pixel $=)$} & & \multicolumn{2}{c}{ TEM $(1$ pixel $=)$} \\
\cline { 2 - 3 } \cline { 5 - 6 } Magnification & $128 \times 128$ & $512 \times 512$ & & $128 \times 128$ & $512 \times 512$ \\
\hline 1,000 & $0.8 \mu \mathrm{m}$ & $0.2 \mu \mathrm{m}$ & & $0.8 \mu \mathrm{m}$ & $0.2 \mu \mathrm{m}$ \\
10,000 & - & - & & $80.0 \mathrm{~nm}$ & $20.0 \mathrm{~nm}$ \\
100,000 & - & - & & $8.0 \mathrm{~nm}$ & $2.0 \mathrm{~nm}$ \\
$1,000,000$ & - & - & & $0.8 \mathrm{~nm}$ & $0.2 \mathrm{~nm}$
\end{tabular}

Note: for a given X-ray spatial resolution (X-ray range), for example, $0.8 \mu \mathrm{m}$, lower magnifications lead to undersampling, whereas higher magnifications lead to oversampling. 


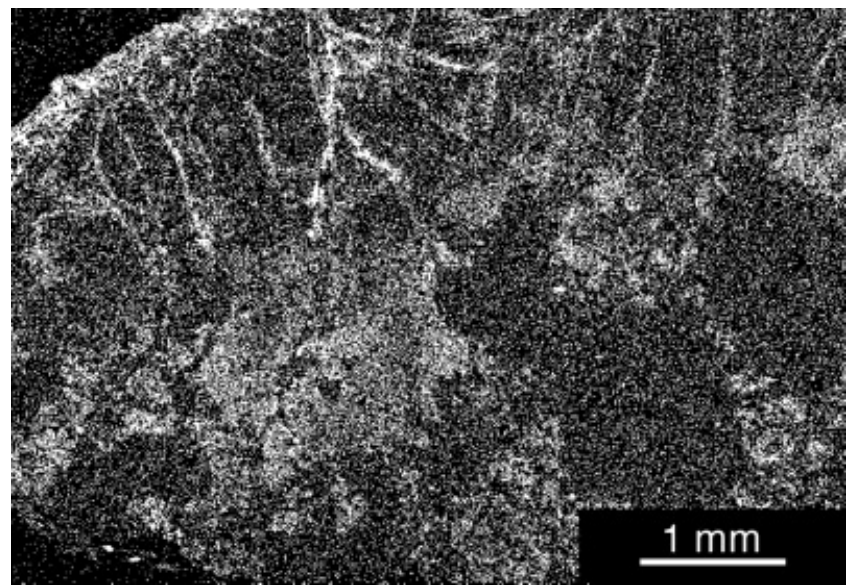

Figure 9. Stage map by WDS of Na levels in the Allende meteorite. The brightest areas represent about $2 \mathrm{wt} \% \mathrm{Na}$, and the darkest area (upper left) represents X-ray background. Acquisition time was $8 \mathrm{~h}$ at $15 \mathrm{keV}$ and $30 \mathrm{nA}$ (Meeker, 1995). (Courtesy of the Meteoritic Society.)

to search for large-scale trends, it is not likely to produce the best quality map. In the AEM, where the thin specimen provides improved spatial resolution, matching the probe size to the pixel size may dictate a high map magnification; for example, in a field-emission dedicated STEM producing a 2-nm beam, this condition occurs at $400,000 \times$ for a $128 \times 128$ map (Lyman, 1986).

For a large field of view, very low magnification is required. It is not recommended that this be accomplished by simply setting the microscope to a low magnification and scanning a large raster because, in addition to the serious underscanning, a loss of intensity may occur at the edges of the map. This effect is sometimes observed with EDS at very low magnifications $(<50 \times)$ if part of the detector's view of the specimen is cut off by the detector collimator. In WDS systems, spectrometer defocusing produces uneven map intensities at magnifications below about $1000 \times$ (see correction methods in section on artifacts). The best lowmagnification maps are produced by keeping the beam stationary and moving the specimen to an array of positions; this assures that the $\mathrm{X}$-ray spectrometer has the same view of the electron beam target area regardless of magnification (see Fig. 9). To be successful the specimen stage scanning movement must be reproducible to about $1 \mu \mathrm{m}$, but this is within the capability of most modern EPMA instruments. Several implementations of stage scanning have been developed to produce low-magnification X-ray maps (Ono et al., 1985; Buskes \& Baughman, 1988; Cantrill et al., 1990; Takahashi \& Okumura, 1998). Another way of obtaining high quality maps at low magnification is to stitch together several higher magnification maps into a collage. This has been done for bulk specimens in the microprobe (Bremier et al., 2000) and for thin specimens in the AEM/ STEM (Papworth \& Williams, 2000).

\section{Maximizing the Collected X-ray Counts}

A common difficulty observed in X-ray maps is the lack of sufficient X-ray counts in each pixel, which makes the map appear noisy. The relative noise fluctuation in a pixel containing $N$ counts is proportional to $\sqrt{N}$. Fiori $(1986 a)$ stated that, for a single-element map, a minimum of $8 \mathrm{X}$-ray counts per pixel is required to make the map pixels statistically significant, which translates to a total of $\sim 130,000$ counts in a $128 \times 128$ map. In a high quality map of an element, the pixel with the largest number of counts might contain hundreds or thousands of counts. For conventional $\mathrm{Si}$ (Li) EDS detectors, higher counts per pixel can be obtained by employing a higher beam current, setting a short pulse processor time constant to increase the count rate capability (up to 50,000 cps over the entire spectrum), and counting for a long dwell time per pixel (100 ms or longer). Silicon drift detectors (Strüder et al., 1999), with their high count rate capabilities, produce X-ray maps of high quality in minutes rather than the hours typical of conventional EDS (see Fig. 7 and the article by Newbury in this issue).

\section{Detection Limits}

The smallest detectable amount of an element, the minimum detectability limit $\left(C_{d l}\right)$ or minimum mass fraction (MMF) detectable, will not be as good for mapped elements as for X-ray analysis in the point mode because the dwell time per specimen location is much shorter in a map. For mapping of bulk specimens, detection limits for most elements are $0.5-1 \mathrm{wt} \%$ for WDS and $2-5 \mathrm{wt} \%$ for EDS (Goldstein et al., 1992). For example, if the beam were scanned long enough to collect 100 counts/pixel, a WDS system with a peak-to-background ratio $(P / B)$ of $\sim 1000$ could detect about $1 \mathrm{wt} \%$ of an element, whereas, a conventional EDS system with a $P / B$ of $\sim 80$ could detect about $3 \mathrm{wt} \%$. In the limit of long acquisition times $(\sim 50 \mathrm{~h})$, the estimated best mapping detectability for WDS is $1000 \mathrm{ppm}$ (0.1 wt\%) (Newbury et al., 1990b). Analyses near the limit of detectability have been reported for bulk specimens (Robinson et al., 1998) and thin specimens (Watanabe et al., 1997; Keast \& Williams, 1999). Silicon drift detectors, with many times the count-rate capability of conventional EDS detectors, should have a minimum detectability limit between WDS and conventional EDS. It should be noted that, in general, X-ray microanalysis of bulk specimens can achieve lower (better) limits of detection than are possible with surface techniques such as Auger electron spectroscopy (Wachtman, 1993), but less than with ion detection techniques (see Table 1).

In conventional EDS X-ray mapping, a region of interest or window is set around preselected X-ray peaks. For the best element detectability, defined as $P / B$ times peak intensity $P$ (Ziebold, 1967), the window width should be 1.2 times the full-width-at-half-maximum (FWHM) intensity of the peak (Sutfin \& Ogilvie, 1971; Fiori et al., 1988). 
However, if the peak of interest is overlapped by a peak from another element, the window may need to be set narrower, reducing the count rate and detectability for that element. For mapping small peaks when background subtraction is possible, a window width that encompasses the full width of the peak is the best choice to collect the most $\mathrm{X}$-ray counts per pixel for that element.

For thin specimens, the X-ray excitation volume under the beam (Fig. $5 \mathrm{~b}$ ) is exceedingly small, about $10^{-6}$ to $10^{-4}$ that of a bulk specimen. Thus, to collect enough counts for a reasonable elemental detectability, the analyst must provide a much larger electron dose (higher probe current and longer counting time) or work in a thicker region of the specimen. In one study comparing FEG and non-FEG AEM instruments in single point mode, the detectability limit was below $0.2 \mathrm{wt} \%$ only for thicker regions of the thin foil and became worse as thinner areas were analyzed to improve spatial resolution (Goldstein et al., 1990). Thus, following the trends noted above, X-ray mapping of thin specimens should exhibit a detectability on the order of $1 \mathrm{wt} \%$. However, this value may be improved (reduced) for AEMs with 200-300 kV field-emission sources, low-X-ray-background objective lenses, high efficiency X-ray detectors, and $C_{s^{-}}$ corrected STEM optics (Lyman et al., 1994; Watanabe \& Williams, 1999; Watanabe et al., 2003). X-ray mapping of thin specimens in a FEG-AEM has an additional advantage. The high spatial resolution $(2-5 \mathrm{~nm})$ allows highmagnification visualization of nanometer-sized phases containing elements in locally detectable concentrations, whereas the same phases/elements may be difficult to detect in electron images (Michael \& Taylor, 1988).

\section{Artifacts}

\section{Autoscaling}

In EDS X-ray mapping, autoscaling of intensity provides a convenient redisplay of an element map when the accumulated number of counts is high. When autoscaling is operating during multipass collection, it lets the viewer perceive areas of different concentration without waiting for the map to finish. However, without knowledge of the scaling factors involved, it is difficult to make comparisons of maps from different elements and different areas of the specimen (Goldstein et al., 2003).

\section{Continuum Image Artifact}

In mapping an element present at low concentration, the $\mathrm{X}$-ray peak of interest and the background continuum are of comparable intensity. Because the bremsstrahlung background intensity is proportional to the average atomic number of the specimen, regions of background in the spectrum with no X-ray peak will rise and fall with average $Z$ across the specimen. Thus, a map for an element present in low concentration (a small peak detected on top of the X-ray background) can exhibit false intensity when the beam

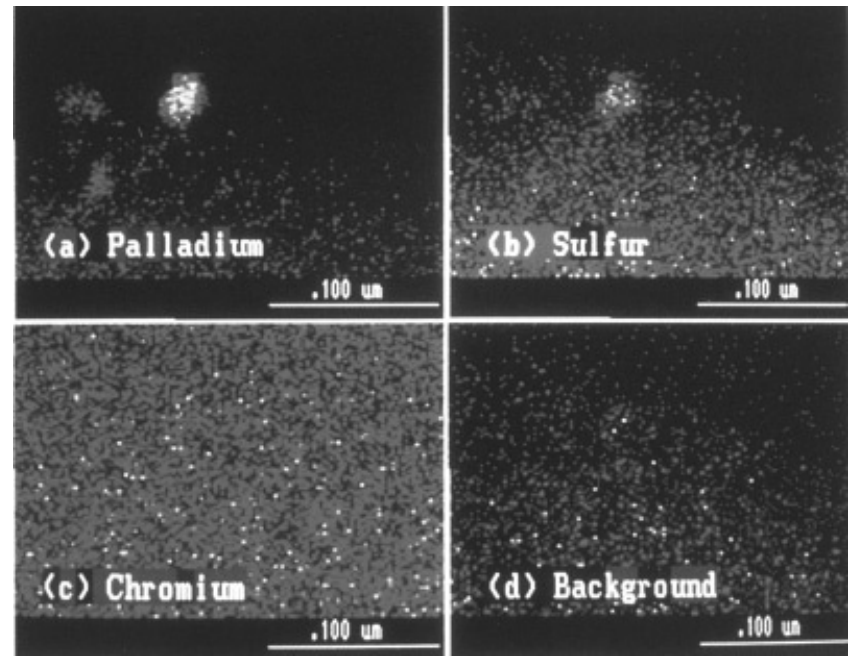

Figure 10. Chromium coating of sulfur-poisoned Pd catalyst to immobilize the mobile sulfur species for STEM analysis. a: Pd X-ray map. b: S X-ray map. c: Cr X-ray map. d: Background X-ray map taken near the S K X-ray line (Lyman, 1992). (Courtesy of the Microscopy Society of America.)

excites background $\mathrm{X}$ rays from heavy elements. An essential test to establish validity of an elemental X-ray map is to set a mapping window for a region of background containing no element $\mathrm{X}$-ray peak. The validity of an X-ray map for an element present at low concentration can be judged by comparing it with a "background" map (the null-element test). It is good practice to collect a background map during every mapping session, compare the background map with each low-concentration element map, and confirm the presence of the element with a point analysis of each phase. Figure 10 illustrates the importance of the background map in the analysis of sulfur in a TEM thin specimen. The background map in Figure 10d was acquired from a window set for a region of background near the sulfur peak. The background map was necessary to ensure that the sulfur image intensity exceeded the background intensity caused by the heavier palladium atoms. Variations in background due to changes in average atomic number of the specimen can be removed by correcting the background map (Myklebust et al., 1989; Newbury et al., 1990b).

\section{High Count Rate Effect}

In mapping with a conventional EDS detector, the number of counts per pixel follows the curve of output count rate versus input count rate. At X-ray count rates less than 2000 cps, this curve is nearly linear. However, at high count rates, the curve has a maximum, meaning that higher input counts will result in fewer counts in the recorded X-ray map. Thus, the map would exhibit lower intensity in regions with the highest concentrations of an element (Fiori, 1986a). 


\section{Beam Intensity Drift}

When a map takes an hour or more to collect, there is always a possibility that the beam current may change, a particular concern for mapping in microscopes employing cold field-emission guns. However, by monitoring the beam current dynamically, the map intensity can be corrected (McCarthy, 1979). Moreover, when the data from many short maps are summed, this effect is insignificant.

\section{WDS Spectrometer Defocusing}

The region on the specimen for which emanating $\mathrm{X}$ rays are exactly focused by the WDS optics is about $100 \mu \mathrm{m}$ by $1 \mathrm{~cm}$ (the width of the analyzing crystal). At magnifications less than $500 \times$, regions of the map on either side of the central $100-\mu \mathrm{m}$ band exhibit significantly fewer counts because of spectrometer defocusing. Thus, to produce an X-ray map in which intensity is directly related to the amount of the element, this defocusing must be corrected. Because defocusing is most serious with a vertical WDS spectrometer, use of an inclined spectrometer minimizes this artifact. The effect can be eliminated by scanning the stage or by dynamically correcting the defocusing with software (Marinenko et al., 1987; Newbury et al., 1990a).

\section{Mobile Species}

Electron-beam bombardment can cause movement of certain atomic species. In bulk glasses, mobile $\mathrm{Na}^{+}$ions migrate toward negatively charged subsurface regions, and anions can be desorbed from the surface in fluorides, chlorides, and oxides (Jbara et al., 1995; Cazaux, 1996). These effects may be observable in long-term X-ray maps. The usual methods for mitigating this problem are the following: rapidly scanning the beam (fast mapping), cooling the specimen, or coating the specimen surface with a carbon or metal film. However, such methods are specimen specific and do not always alleviate the problem. In thin specimens for AEM mapping, sulfur can be a difficult mobile species to map (Lyman et al., 1987). Coating the surface of the specimen with $10 \mathrm{~nm}$ of $\mathrm{Cr}$ (see Fig. 10c) reduces the mobility of sulfur so that it can be routinely mapped to show its association with metal catalyst particles (Reuter \& Lyman, 1991; Lyman, 1992).

\section{Electron Probe Shape Effects in AEM}

The predicted spatial resolution for AEM in Table 2 will not be achieved if the electron beam has significant nonGaussian tails in its intensity distribution at the specimen. Beam-tailing occurs when the STEM beam-limiting aperture is too large and spherical aberration produces a beam in the shape of a tall "witch's hat" (Cliff \& Kenway, 1982; Colliex \& Mory, 1983). High excitation of the first condenser lens can worsen these beam tails. Figure 11 shows

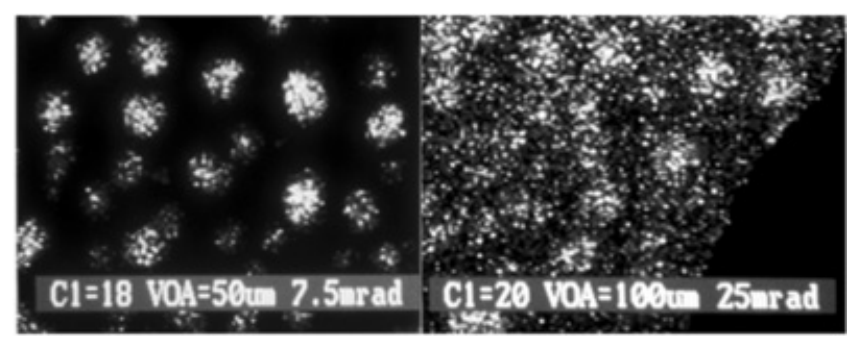

Figure 11. Electron probe shape effects. X-ray maps of Au islands ( $\mathrm{Au} \mathrm{L}_{\alpha}$ line) on a carbon film taken under different electron optical conditions in a dedicated STEM. The best X-ray map (left) employed a beam without tails using a weaker first condenser lens $(\mathrm{C} 1=18)$ and a smaller beam limiting aperture $(\mathrm{VOA}=50 \mu \mathrm{m})$. Large beam tails (right) are responsible for the poor contrast on $\mathrm{Au}$ islands in the image taken with a stronger condenser lens $(\mathrm{C} 1=$ 21 ) and a larger beam limiting aperture $(\mathrm{VOA}=100 \mu \mathrm{m})$. Image width $=100 \mathrm{~nm}$. (Courtesy of J. Michael.)

the effect of poor electron probe shape on X-ray maps of gold islands supported on a carbon film.

\section{Effect of "Hole Count" in AEM}

Spurious X-ray background will reduce contrast in X-ray maps and can produce misleading results. High-energy electrons hitting metal components in the illumination system produce bremsstrahlung $\mathrm{X}$ rays that can penetrate fixed and movable apertures. Thus, a wide $\mathrm{X}$-ray beam from the electron column bathes the entire specimen and excites fluorescent $\mathrm{X}$ rays from regions of the specimen not under the electron probe (Williams \& Goldstein, 1981; Allard \& Blake, 1982). This problem can be controlled at $100 \mathrm{kV}$ by installing 1-mm-thick beam-limiting apertures in the condenser lens system, but this effect may still be a problem in AEMs operated at 200-400 kV. The extent of the problem can be assessed with a suitable test specimen (Egerton \& Cheng, 1994; Bennett \& Egerton, 1995).

\section{Specimen Drift in the AEM}

Drift is not a problem in SEM/EPMA specimen stages; however, drift can significantly alter X-ray maps of thin specimens. In cold field-emission AEMs, the probe size is about $2 \mathrm{~nm}$, and map magnifications above 500,000 $\times$ are common. Acquiring such a map over an hour severely tests the stability of any mechanical specimen stage. Drift in sequentially collected X-ray maps manifests itself as a distortion in the image, for instance, a circular shape appears ellipical. This effect can be corrected dynamically with specimen tracking software (Vale, 1987) or by comparing STEM images before and after short maps and correcting drift by deflecting the scan raster (Tsuneta et al., 2002). A correction also can be applied after the completion of map acquisition by use of image manipulation software (Long, 1990). Meth- 
ods for correcting specimen drift in biological specimens have been proposed by Lamvik et al. (1989).

\section{Specimen Thickness Effects in the AEM}

For a thin specimen, X-ray intensity increases as the element concentration increases and as specimen thickness increases. Recent methods can correct for the thickness effect and even produce a map of the specimen thickness (Williams et al., 2002). Thickness variations can also be tracked by collecting the electron energy loss spectrometry (EELS) spectrum along with the X-ray counts at each pixel (Malis et al., 1988; Egerton, 1996).

\section{Background Subtraction}

X-ray background counts under a characteristic peak are unrelated to the element being mapped and should be subtracted. Background subtraction at each pixel is useful to improve contrast in qualitative maps, but it is essential for quantitative maps. One approach is to collect a background map from a spectral region near the element peak and subtract the background map from the element map. This may be sufficient for improving qualitative maps even though the background intensity may not be random (continuum image artifact).

For quantitative mapping, corrections at each pixel for background variations with specimen density are essential. Calculation schemes for removing this specimen-density variation effect have been developed for both WDS and EDS maps (Fiori et al., 1984; Myklebust et al., 1989). A background map, properly corrected for specimen density variations, should show random intensities in the pixels and should not exhibit evidence of specimen features. Only then is the background map suitable for quantitative subtraction from an element map.

\section{Display of Qualitative Maps}

\section{Image Processing}

Digital image processing can be defined as a group of operations that act on an image to produce a modified image. Generally, these operations are done to "improve" the image in some way; however, when applied to compositional images, they can have the effect of seriously changing the raw data. There are times when one may wish to smooth noisy data or enhance areas such as edges. Nevertheless, these operations alter the data and should be avoided. One must be cautious about using histogram operations such as equalization or contrast stretching (Russ, 1999). In a like manner, kernel filters such as smoothing or sharpening operations and gradient filters such as edge finders must be used with caution, if at all. For example, the excessive use of smoothing on an image with in low intensity in each pixel can result in artifacts called "smoothing worms" (Fiori, 1986a). Fiori also showed the use of differential filters to look for trace-element gradients in long-duration maps. In general, image processing of compositional images is done for display purposes, not for analysis. If image processing is used, a raw original map should be preserved for comparison.

\section{Use of Color}

\section{Intensity Levels and Color}

Color can enhance the visibility of intensity levels in a map because the human eye can distinguish many more shades of color than gray levels. The dynamic range of the eye is quite large at about $10^{10}$ levels, but it can distinguish only about 20 levels of gray on a photographic print (Fiori, 1986a). Many more shades of color can be discriminated; Nickerson and Newhall (1943) estimated 1.9 million shades under typical viewing conditions. This value has been confirmed by recent workers (McCamy, 1998; Pointer \& Attridge, 1998). Many variables, such as the ability of the observer, the darkness of the surroundings, and the characteristics of the display, affect these estimates. Regardless of the actual number, it is clear that hundreds of thousands of different shades of color can be perceived, making color an obvious way to display elemental concentrations. Additionally, there is the consideration that the human eye can observe fewer levels (color and gray levels) in reflection off a print than when looking at a computer monitor.

\section{Pseudocoloring}

False color (pseudocolor) is often used for display of different elements. However, the colors employed, usually chosen by the manufacturer, can mislead the viewer. Because the eye is sensitive to certain colors more than others, the viewer may receive a misleading impression of the relative concentration among a series of element maps.

Pseudocolors are also used for intensity scales, sometimes known as look-up tables (LUTs), that help the eye discern specific intensity differences within a single-element map. Many LUTs for coding intensities are used, but most require an explanation (color scale) to understand their meaning. Figure 12 shows an example of color intensity levels in four X-ray maps of a metal particle in a chrondrite (stony) meterorite. The color scale has been selected to emphasize the difference between low-concentration levels in the $\mathrm{Cr}$ and $\mathrm{P}$ maps (black-blue-green) and highconcentration levels in the $\mathrm{Ni}$ and $\mathrm{S}$ maps (orange-redwhite). These colors also can be labeled to represent X-ray counts or even matrix-corrected compositions. The thermal scale is the most intuitive color table for display of the map intensities of a single element (Bright \& Newbury, 1991; Bright \& Marinenko, 1992). The thermal scale is a scale of incandescence, the color temperature of a black body as its temperature rises (red-orange-yellow-white). Figure 13 is an example of how the thermal scale can display concentration variations in a single-element map. 


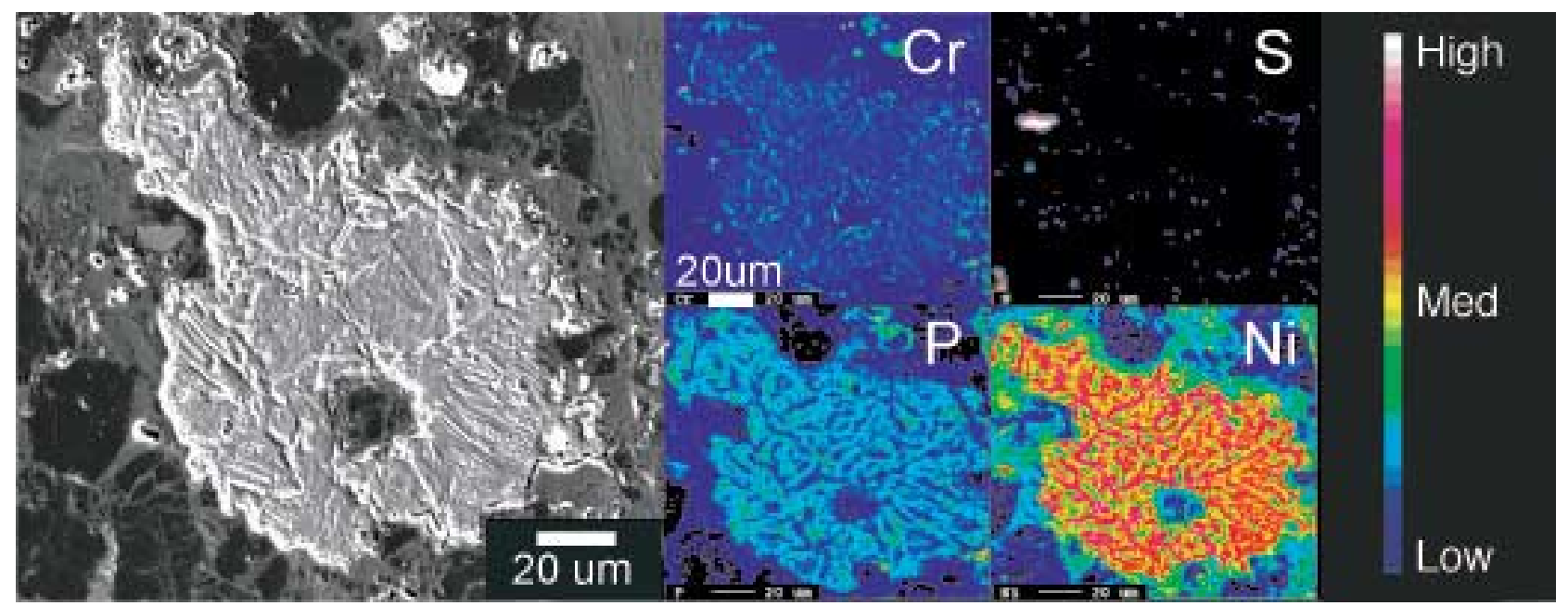

Figure 12. Pseudocolor coding of map intensities. X-ray maps of a Ni-rich metal particle in a $\mathrm{CH}$ chondrite (stony meteorite) known as Acfer 214. SEM image of the etched flat surface (left) and four WDS X-ray maps showing the distributions of $\mathrm{Cr}, \mathrm{S}, \mathrm{P}$, and Ni. Color scale (right) indicates the relative number of X-ray counts per pixel. (Courtesy of J.I. Goldstein, R.H. Jones, P.G. Kotula, and J.R. Michael.)

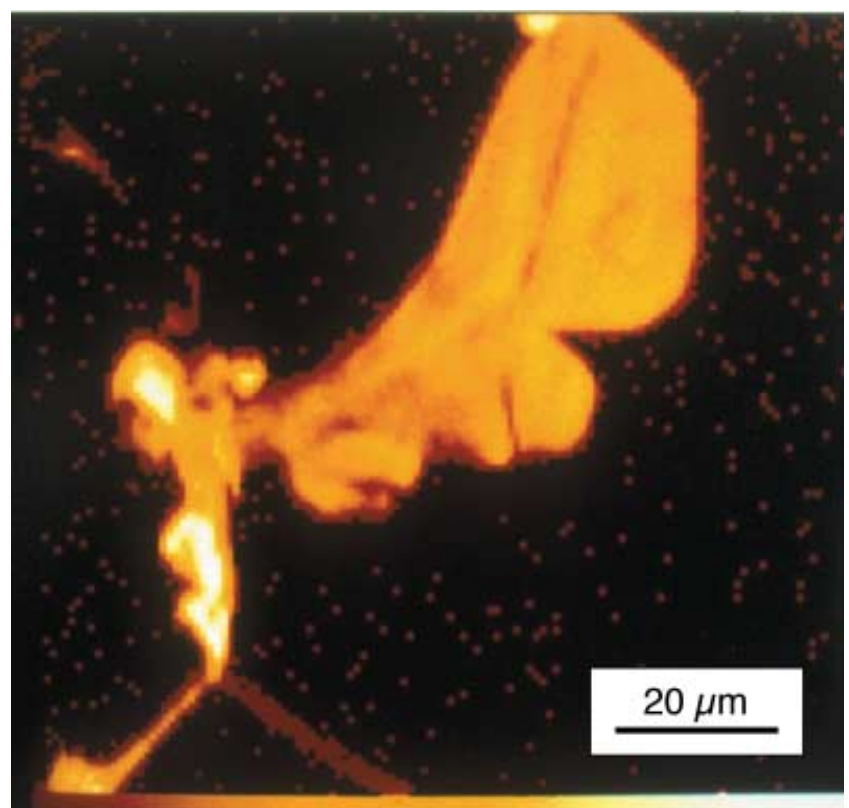

Figure 13. Quantitative compositional image of zinc at grain boundaries in copper. The thermal intensity scale is used to represent the variation in zinc from $0 \mathrm{wt} \%$ (red) to $10 \mathrm{wt} \%$ (white). Image width $=100 \mu \mathrm{m}$ (Goldstein et al., 2003; Newbury, 1992). (Courtesy of Springer Science.)

Another use of pseudocolor is called logarithmic threeband scaling. Trace, minor, and major amounts of an element can be shown in a single image by assigning a different color to each of three decades of concentration level (Newbury \& Bright, 1999).

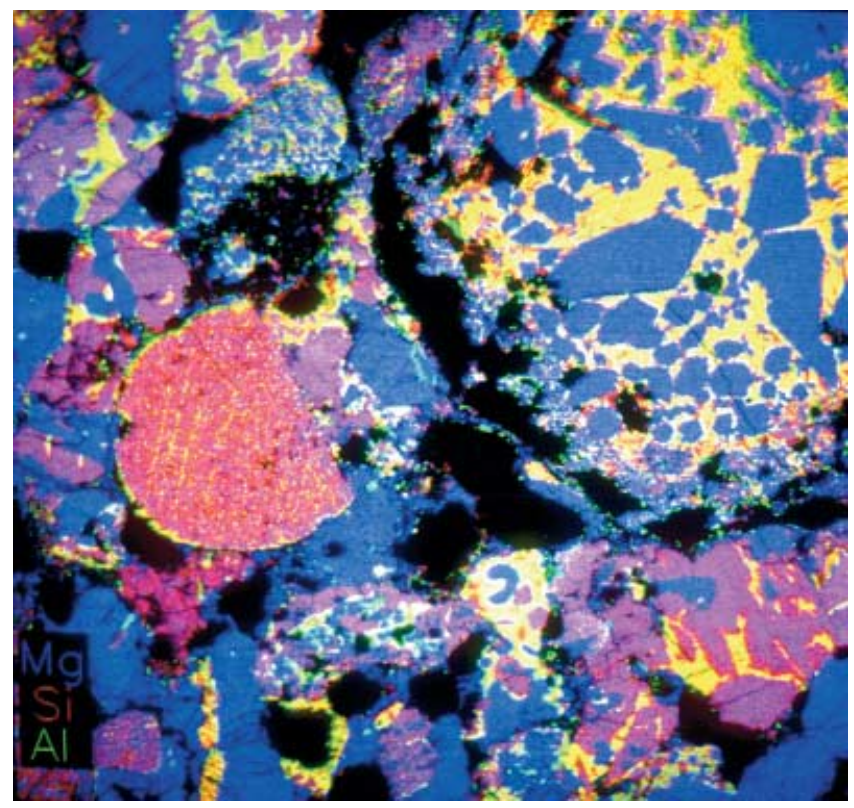

Figure 14. Primary color X-ray map of a carbonaceous chondrite meteorite. Blue represents $\mathrm{Mg}$, red represents $\mathrm{Si}$, and green represents Al. Yellow in the map indicates locations where Si (red) and $\mathrm{Al}$ (green) are colocated. Image width $=1 \mathrm{~mm}$ (Fiori, 1986a). (Courtesy of Springer Science.)

\section{Primary Color Images}

Superimposing three elemental maps that have been assigned primary colors (red, green, blue) provides a simple method for determining elemental associations. Because the 
colors red, green, and blue form specific colors when combined on a computer monitor, elemental associations are clearly shown in a single primary color image. Figure 14 shows a primary color image of a flat-polished section of a carbonaceous chondrite meteorite in which Si has been assigned the color red, $\mathrm{Al}$ green, and $\mathrm{Mg}$ blue. From the combination of primary colors, it is clear that the yellow regions contain both $\mathrm{Si}$ and $\mathrm{Al}$, whereas the purple regions contain both Si and Mg (Fiori, 1986a).

\section{Visual Perception}

In digital X-ray maps, it is possible for a person to perceive differences in concentration levels even if the highest elemental concentration is represented by only a few counts per pixel. This phenomenon occurs because the human brain is able to find gradients while suppressing background in accordance with Weber's Law, a well-known principle in psychology. Human ability for discrimination is further enhanced by computer autoscaling during map acquisition and the use of color rather than gray scale. Several investigators have shown that useful information may be obtained from thin-specimen compositional images when only a few counts per pixel are recorded (Michael \& Taylor, 1988; Garratt-Reed, 1990). These investigators found that even when the number of X-ray counts is not statistically significant, the eye is able to integrate over several pixels to qualitatively show the presence of small precipitates or thin layers in their expected locations.

\section{Concentration-Concentration Histograms}

Correlations of one element with another can be made with concentration-concentration histograms (CHIs). These scatter-type diagrams, constructed from two or three elemental images, provide a visual means to determine how elements are associated with one another in the specimen (Bright \& Newbury, 1991; Bright \& Marinenko, 1992). In a $\mathrm{CHI}$, the X-ray intensities recorded for two elements at the same image pixel are plotted against one another. Using software developed at the National Institute of Standards and Technology (NIST) to select a group of pixels in a certain composition range (an area on the $\mathrm{CHI}$ ), the image region having this composition can be reconstructed in a "traceback" image (Bright \& Newbury, 1991).

An illustration of CHI manipulation is shown in Figure 15 for the bulk specimen analysis of a corroded Japanese sword blade. For any point on these $\mathrm{CHI}$ diagrams, the vertical axis of the $\mathrm{CHI}$ shows the carbon X-ray intensity at a pixel, whereas the horizontal axis shows the iron X-ray intensity at the same pixel (Fig. 15a,c). The intense group of pixels circled at the bottom of Figure 15a corresponds to the low-C, high-Fe pixels, that is, the matrix. The reconstructed traceback image of these pixels shows the Fe-rich matrix (Fig. 15b). The traceback image from the circled high-C region of the $\mathrm{CHI}$ reveals the iron carbide phase (Fig. 15d).
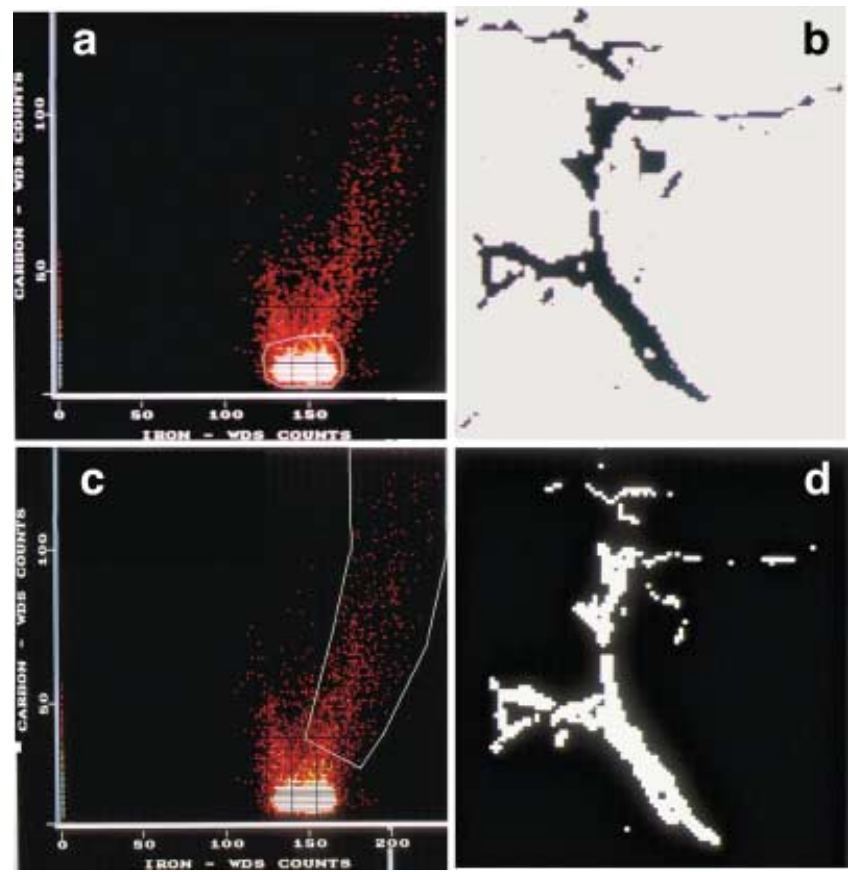

Figure 15. Concentration-concentration histograms of a corroded Japanese sword from data collected with WDS in an EPMA. The number of iron counts is plotted on the horizontal axis whereas the number of carbon counts is plotted on the vertical axis. The iron oxide matrix is represented by the high intensity region of the histogram. The circled group of matrix pixels (a) is redisplayed as the image of the matrix (b). When the region of the histogram high in both iron and carbon (c) is redisplayed, the iron carbide region of the specimen is shown (d). Specimen courtesy of M. Notis; histogram construction courtesy of D. Bright. Image width $=70 \mu \mathrm{m}$ (Lyman, 1992). (Courtesy of the Microscopy Society of America.)

For three-dimensional CHIs, elements are selected three at a time, forming three-dimensional scatter diagrams. Clusters of pixels related to a particular phase can be difficult to visualize within the cube of data. Using principal component analysis (PCA), clusters of related pixels representing different phases can be determined unambiguously, an improvement over manual methods (Bright, 1995).

\section{Image Comparison}

Parts of an X-ray map can be selected for viewing or analysis by setting thresholds on the gray scale image or the color look-up table. Because these images have compositional contrast, however, a useful way to segment them is a class of operations generally called Image Math (Russ, 1999). In these methods, a computer searches the data for a selected range of intensities to make arithmetic or Boolean comparisons on the data set. The result is a new image with contrast in only those regions corresponding to the screening conditions. The most common application of this technique consists of screening X-ray maps to establish a 


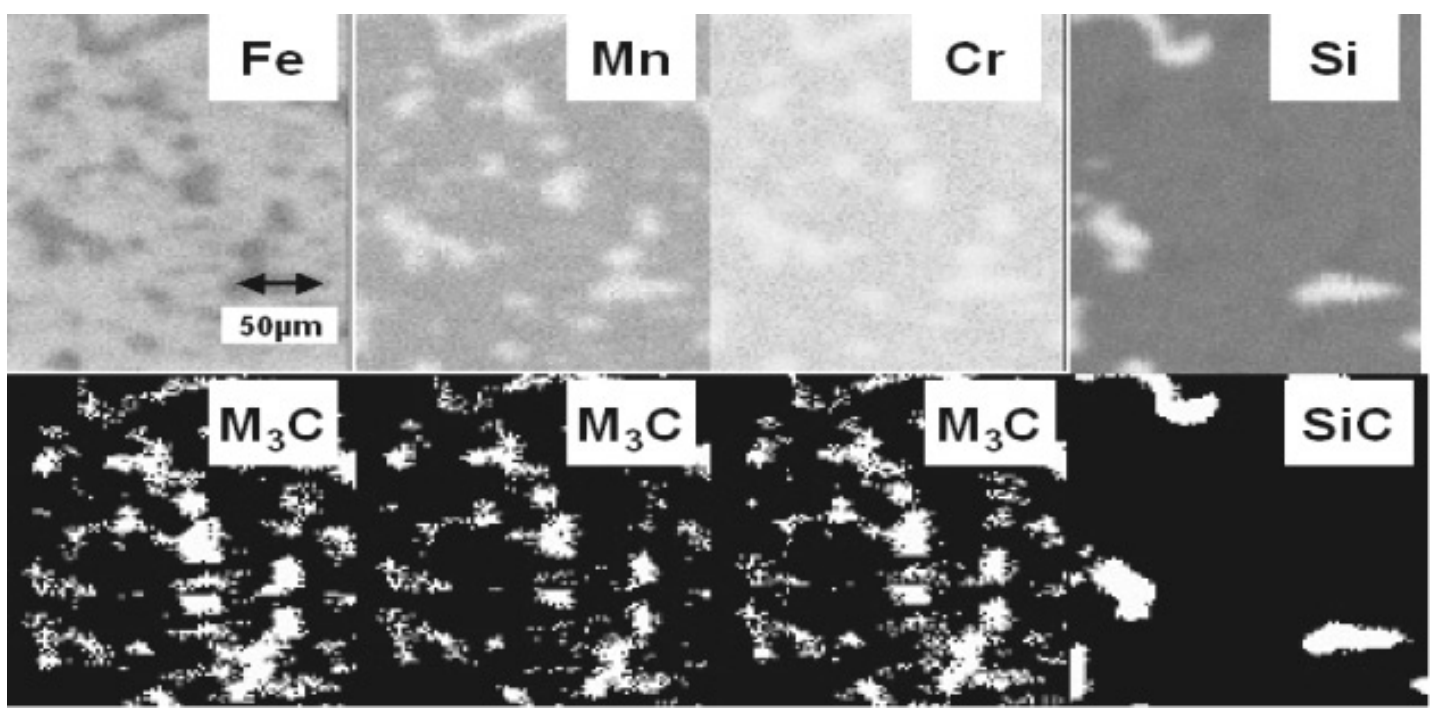

Figure 16. Image comparison using Image Math. Maps of $\mathrm{Fe}, \mathrm{Mn}, \mathrm{Cr}$, and $\mathrm{Si}$ in steel after screening for carbides, where the screening condition was the following: carbon intensity $>270$ counts. Top row shows element intensity; bottom row shows binary images of elements in carbides after screening. Two different types of carbides were revealed by this method: $(\mathrm{Fe}, \mathrm{Mn}, \mathrm{Cr})_{3} \mathrm{C}$ and $\mathrm{SiC}$.

concentration range and then displaying the X-ray map pixels that correspond to the screening condition.

An example of the use of Image Math is shown in Figure 16. The top row of images are X-ray maps of Fe, Mn, $\mathrm{Cr}$, and $\mathrm{Si}$ in a steel that was heat treated for several months to grow carbides. The second row shows the output of a screening operation. The screening condition was carbon intensity $>270$ counts for display at a pixel. This criterion selects only the carbides. The maps for $\mathrm{Fe}, \mathrm{Mn}, \mathrm{Cr}$, and $\mathrm{Si}$ are then redisplayed under the screening constraint (lower row of maps). These images show that $\mathrm{Fe}, \mathrm{Mn}$, and $\mathrm{Cr}$ substitute freely in the $\mathrm{M}_{3} \mathrm{C}$ carbide structure, but $\mathrm{Si}$ forms a distinct carbide ( $\mathrm{SiC})$.

Another example of Image Math involved the determination of alkali exsolution in a basaltic glass considered for nuclear waste disposal (Friel, 1987). In this application, the logical 〈exclusive or〉 comparison revealed Na-rich and K-rich glass phases that were not evident in the electron image or in selected quantitative analyses.

\section{Quantitative Maps}

\section{Bulk Specimens}

Quantitative X-ray maps of bulk specimens were demonstrated even before the development of digital techniques (Heinrich, 1962a, 1962b). Later, a special cathode ray tube provided a display of X-ray intensities in nine steps of brightness (Tomura et al., 1968). Digital data collection and processing have made quantitative maps reliable and routine (Statham, 1988; Anderhalt \& Sandborg, 1989; Newbury et al., 1990b). Numerical values for the X-ray intensity of an element are stored at each pixel, and some scheme is applied to subtract the background X-ray counts. An X-ray intensity map for an element may be corrected through standardsbased atomic number/absorption/fluorescence (ZAF) matrix correction procedures (Goldstein et al., 2003) to reveal the quantitative composition at each pixel location (Newbury et al., 1991). An alternative to performing a quantitative analysis on a pixel-by-pixel basis is to sum pixels within a single phase and perform the quantitative analysis once on the summed X-ray counts for each element. Because a large number of counts from each phase can be collected in this way, the precision is high. An example of this sum method is given for a ceramic that exsolved into two phases (Friel \& Greenhut, 1997). The advantage of pixel-by-pixel analysis is that elemental concentrations can be visualized in the quantitative map, and local variations become evident. Figure 17 compares X-ray intensity maps with full quantitative maps, which may be interrogated for the concentration of each element on a pixel-by-pixel basis by placing the cursor on that particular location.

\section{Instrumental Correction Factors}

Before applying ZAF matrix corrections, WDS spectrometer defocusing and EDS spectrometer dead time effects must be corrected (Newbury et al., 1990a). The next task is to subtract the X-ray background, which may be accomplished by subtracting a background image collected near the element X-ray peak (Myklebust et al., 1989). Another method involves removing the background "on the fly" (Fiori, 1986a). If enough counts are collected at a pixel, a digital filter may 


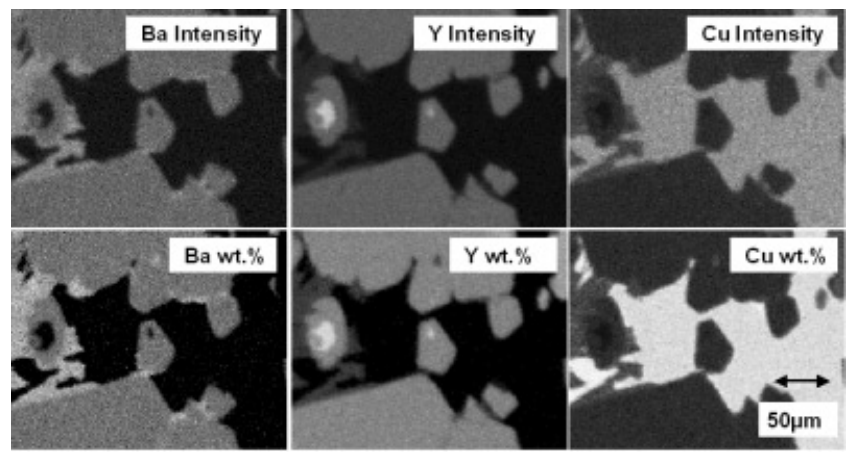

Figure 17. Comparison of digital X-ray intensity maps (top row) with full quantitative maps (bottom row). The specimen consists of several phases in the system $\mathrm{BaO}-\mathrm{Y}_{2} \mathrm{O}_{3}-\mathrm{CuO}$. With appropriate software, the concentration of each element in the quantitative maps can be read out by mousing over the pixels.

be run over the collected spectrum, and a numerical value for each background-subtracted peak can be stored at the pixel location rather than the raw X-ray counts.

\section{Matrix Correction Factors}

On flat-polished bulk specimens, quantitative X-ray maps can be obtained by collecting the appropriate X-ray intensities from each pixel, subtracting the background intensity, dividing by the intensity from a standard containing the element, and then multiplying by the appropriate ZAF or phi-rho-Z correction factors (Armstrong, 1988; Goldstein et al., 2003). It is important not to normalize the results because the raw analytical total also contains information. If the analytical total is low for a group of pixels in a region of the specimen, it may mean that an additional, unexpected element is present (Goldstein et al., 2003). Details of quantitative X-ray mapping (compositional mapping) with the EPMA are given by Newbury et al. (1990a, 1990b). An example of a quantitative X-ray map is shown in Figure 13, where the intensity scale is calibrated to show the local percentage of $\mathrm{Zn}$ at each pixel.

\section{Thin Specimens}

Quantitative images of thin specimens are possible for both inorganic materials and biological specimens, although relatively few have been published. The main reason is the dramatically reduced number of counts collected at each pixel, about $10^{5}$ times smaller than for a bulk specimen.

\section{Inorganic Materials}

An early example of a quantitative thin specimen image, using the method of Cliff and Lorimer (1975) for correcting the background-subtracted X-ray intensities at each pixel, was published by Hunneyball et al. (1981). In thin metal specimens, this technique has been refined to permit quan- titative maps with 2-5 $\mathrm{nm}$ spatial resolution (Watanabe et al., 1997; Keast \& Williams, 1999). By employing a modification of the original $\xi$-factor approach (Watanabe et al., 1996) to quantitation, X-ray absorption effects can be removed on a pixel-by-pixel basis without prior knowledge of the specimen thickness (Williams et al., 2002). This leads to quantitative maps showing specimen thickness and spatial resolution variations, in addition to the elemental concentrations (see Fig. 18).

\section{Biological Specimens}

Cryosections have been used to immobilize ions for quantitative maps of elements in biological thin specimens. Results have been published by several groups (Somlyo, 1984; Fiori et al., 1988; Ingram et al., 1988; Wong et al., 1989; Schultz et al., 1999), who have usually used the Hall method (Hall, 1979; Hall \& Gupta, 1982) for converting X-ray intensities to compositions. In comparison with quantitative EELS, quantitative X-ray procedures are easier to apply because they may be obtained from thicker specimens, they are more tolerant of mass-thickness changes, and they require less-complicated software for spectral processing. The subject of biological microanalysis including X-ray mapping has been covered in a book by Warley (1997).

Special problems arise in the X-ray mapping of biological specimens because they are composed of low atomic number elements with relatively low X-ray yields, giving a poor signal for mapping purposes (Somlyo, 1984). Some specimens may contain high concentrations of elements as a result of some perturbation in a local region, and such high concentrations in certain organisms are localized within distinct compartments (Zierold et al., 1991). These types of specimens provide the most dramatic type of map. Conventional fixation processes sometimes can be used to demonstrate such effects, as in the analysis of iron in ferritin molecules in the human liver (A. Warley, pers. comm.). It is important to be able to account for local differences in mass thickness to be sure that any observed differences in element distribution are not merely due to differences in mass (Fiori, 1986b). The advent of digital imaging allowed mathematical manipulation of collected images, making it feasible to collect both peak and continuum (background) maps. From these it is possible to determine peak/continuum ratios, which are the basis of the Hall method. Provided that a calibration constant has been determined for the element of interest, peak/continuum maps can be converted to fully quantitative images (Ingram et al., 1988; LeFurgey et al., 1992).

\section{Special Quantitative Methods}

Because modern X-ray maps are acquired in digital form, it is possible to combine image analysis data with qualitative or quantitative point analyses to characterize the microstruc- 


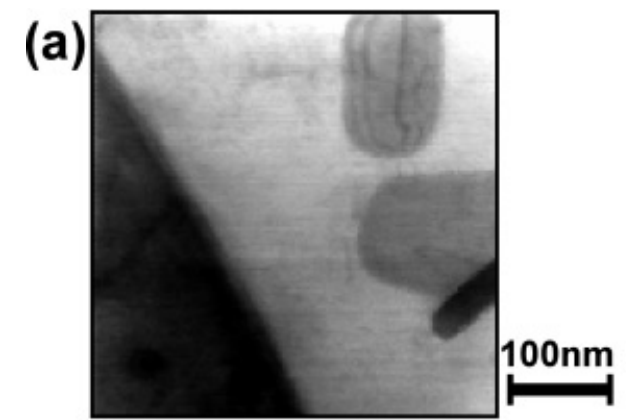

(c)

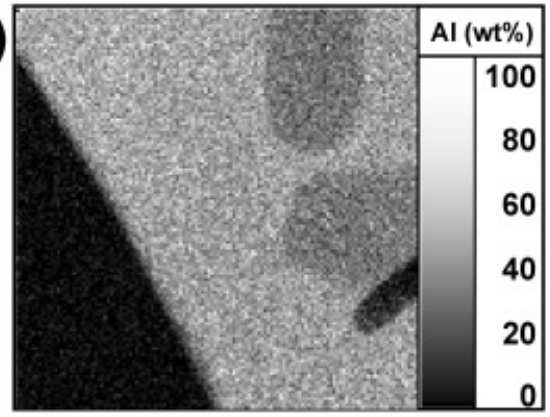

(e)

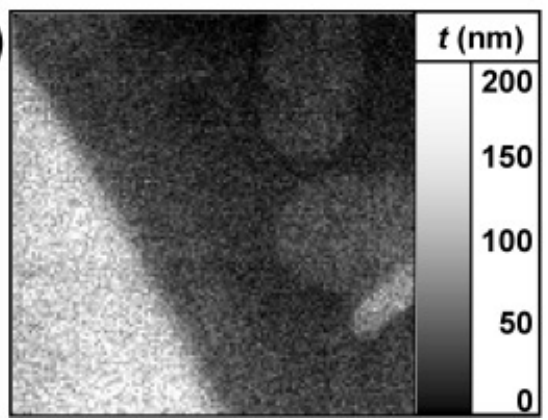

(b)

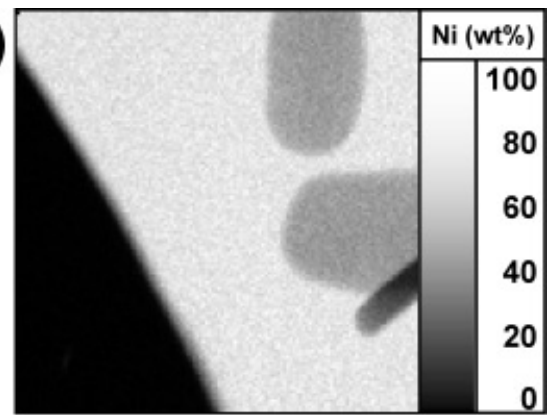

(d)

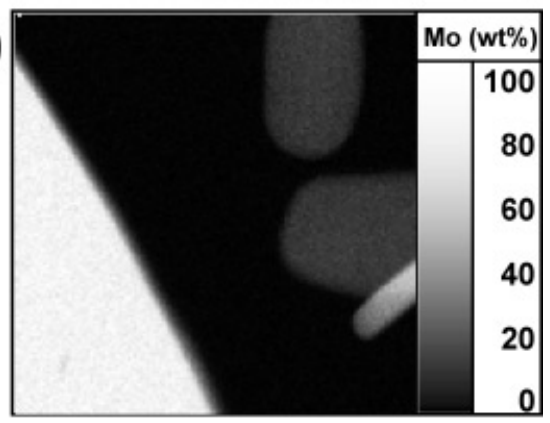

(f)

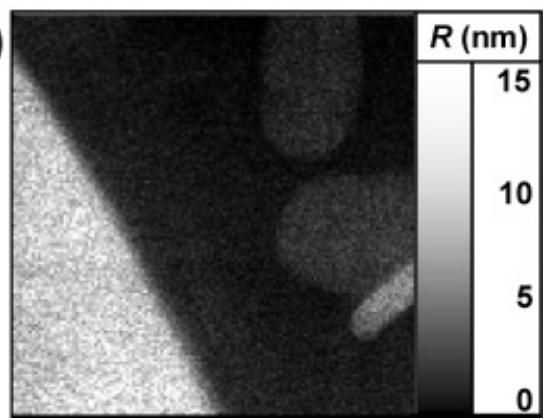

Figure 18. Quantitative X-ray maps from a thin specimen of a Ni-Al-Mo ternary eutectic. The image gray scale represents the composition or parameter shown on the right of each figure. a: Bright-field STEM image. b: Ni map. c: Al map. d: Mo map. e: thickness map. f: Spatial resolution map (Williams et al., 2002). (Courtesy of the Japanese Electron Microscopy Society.)

ture more thoroughly. Two such methods are particle characterization and chemical classification.

\section{Particle Characterization}

An early particle recognition and characterization system combined image analysis with X-ray analysis (Hoover et al., 1975). This technique was invented just after the development of digital beam control in electron-beam instruments and involves driving the beam to particles found in the backscattered electron (BSE) or secondary electron (SE) image. When a particle is encountered, the beam is deflected to measure the extent of the particle at a selected number of angles. Size and shape data for the particles are then combined with the X-ray data to classify them into various predetermined categories (Lee et al., 1978; Kelly et al., 1980; Fritz et al., 1981).

\section{Chemical Classification}

An extension of the particle recognition and characterization method is often called chemical classification, as described by Ekelund and Werlefors (1976). In this method, an image of the entire field is collected, and image analysis is used to measure the sizes and shapes of features. Rules based on size or shape are applied, and the electron beam is driven to those features to collect a short spectrum. The particles or grains thus selected are then classified by a set of rules based on chemistry. This method is faster than the particle recognition method described above because the image can be acquired rapidly and only selected features in the image are subjected to X-ray analysis. Another early implementation of chemical classification was specifically designed to assess the distribution and association of minerals in an ore sample and to predict the liberation yield 


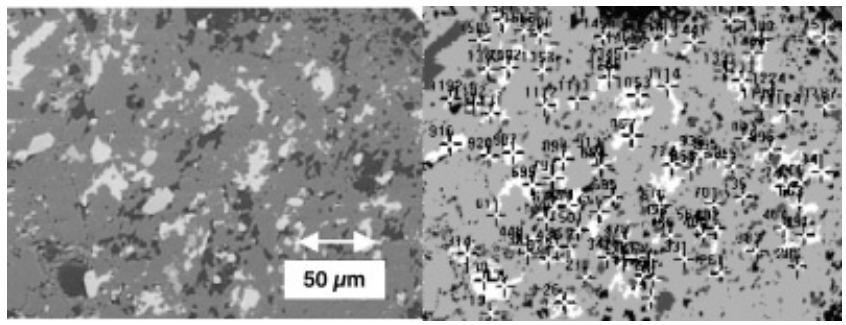

Figure 19. BSE image of the microstructure of a sulfide ore before (left) and after (right) chemical classification. The features whose diameters are $>10 \mu \mathrm{m}$ are displayed in white. The 91 grains analyzed are classified into the classes shown in Table 3.

(Miller et al., 1982). An example of chemical classification is shown in Figure 19. In this specimen, sulfide ore minerals are present in a siderite $\left(\mathrm{FeCO}_{3}\right)$ matrix. There is more than one type of sulfide, however, and some of the sulfide grains contain silver. Inasmuch as the silver content is not revealed in SE/BSE contrast, X-ray analysis is necessary to assay the grade of the ore. In this case, the image analyzer was set to detect grains $>10 \mu \mathrm{m}$ in diameter and classify them in accordance with chemical classes of various minerals. Each detected grain is marked on the image and identified with a number (Fig. 19, right). The results in Table 3 show that 12 of the 91 grains analyzed are classified as Ag-rich. The power of this technique lies in the flexibility for the analyst to design the classification rules to fit the analysis.

\section{Line Profiles}

Most modern EDS mapping systems allow profiles of elemental X-ray intensity to be constructed by drawing a line between any two pixels. Usually there are so few counts in each pixel that such a profile can only be qualitative. However, in the special case of a map that depicts parallel regions of a coating or layered structure, high quality line profiles suitable for quantitation can be obtained by summing equivalent line profiles that run perpendicular to the layers (Kawasaki et al., 1998).

Table 3. Results of Chemical Classification for the Material Shown in Figure 19 but from a Different Area

\begin{aligned} \hline No. of grains & \multicolumn{1}{c}{ Chemical class } \\ \hline 23 & Ag-poor sulfide \\ 12 & Quartz \\ 12 & Ag-rich sulfide \\ 51 & Siderite \\ 2 & Unclassified \\ 91 & Total number of particles \end{aligned}

\section{Full Spectrum Methods}

If the computer-based X-ray analysis system can collect and store an entire spectrum at each pixel, an entirely new set of analytical capabilities are possible. Elements of interest do not need to be identified before starting the map, and the data set may be mined for information at a later time away from the microscope. Thus, without the operator providing information about the specimen, these methods can produce elemental maps for any element present, construct spectra from any image region, and produce quantitative maps.

\section{Spectrum-Image Acquisition}

There are two ways to collect an entire spectrum at each pixel: sequential collection of a spectrum at each pixel and position-tagged spectrometry. Because the resulting data cube is the same, we will use the general term spectrum image for both acquisition modes.

\section{Sequential Spectrum Imaging}

Sequential spectrum imaging was first described in relation to EELS of thin specimens (Jeanguillaume \& Colliex, 1989). Hunt and Williams (1991) developed such a system for EELS and briefly described its application to EDS. Both groups called their technique "spectrum imaging," and the resulting data structures were "spectrum images." In these systems, the spectra were collected pixel by pixel in STEM mode, as the electron beam stepped across the specimen. Most manufacturers of X-ray spectrometers for SEMs have implemented some method for acquiring spectrum images. Figure 20 shows a sequential spectrum image collected from a flat-polished specimen with a commercial system.

Even though today's computers no longer impose a speed limitation on data collection, the physics involved with X-ray production and detection does limit the data rate. Even at maximum EDS detector throughput settings (50-60\% dead time), long mapping times are required to develop a reasonable spectrum at each pixel. For example, a $128 \times 128$ map takes nearly $5 \mathrm{~h}$ using a $1-\mathrm{s}$ dwell time per pixel. Once the data are acquired, a three-dimensional data cube consisting of $x, y$, and energy is stored in the computer. The data cube can be "mined" later to display maps of any element or the spectrum from any single-phase region within the map. Each spectrum image requires at least $20 \mathrm{MB}$ of storage capacity, but this is not a problem with modern computers. The length of time to acquire a highquality sequential spectrum image places considerable demands upon the stability of the microscope both in terms of beam intensity and specimen drift.

\section{Position-Tagged Spectrometry (PTS)}

In an alternative acquisition method for spectrum images, the electron beam is continuously scanned while $\mathrm{X}$-ray data 

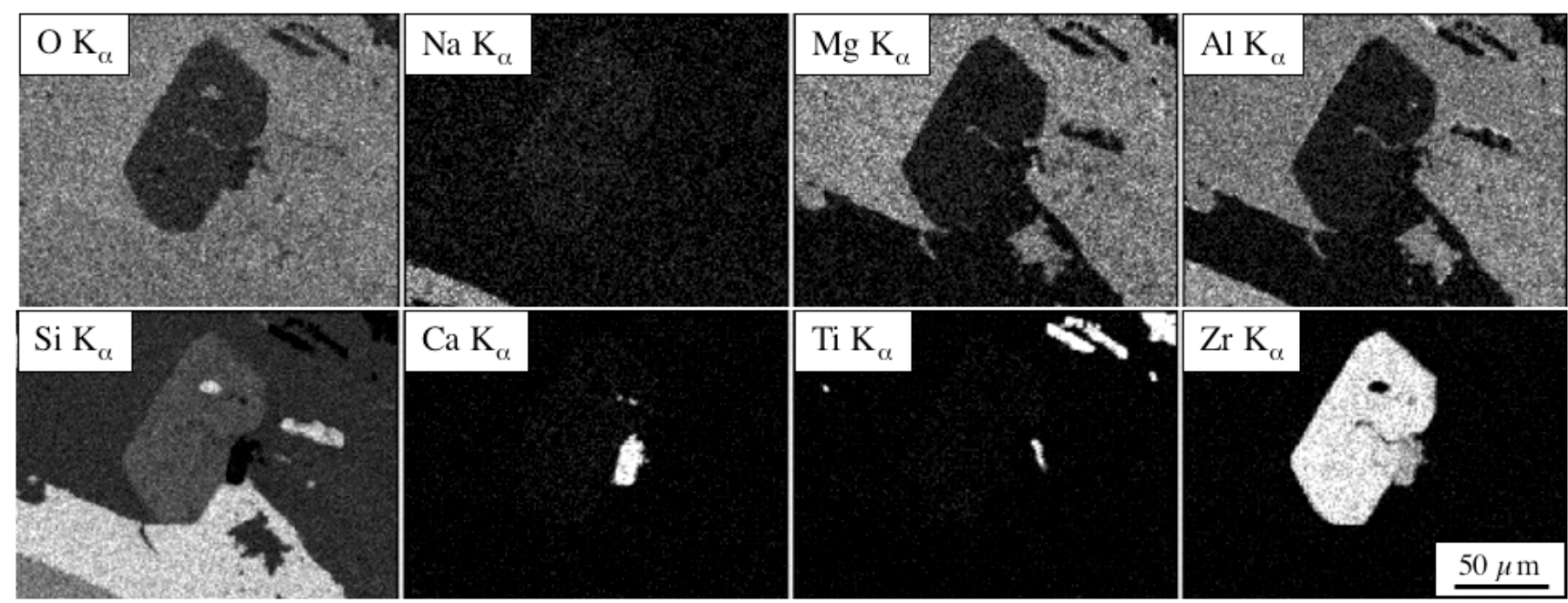

Figure 20. Sequentially collected spectrum image from a flat polished section of granite. Elements in large concentrations were expected, but certain elements in low concentration were revealed by mining the spectrum image (Na, Ca, and Ti). (Courtesy of David Rohde, Thermo Corp.)

are streamed to the computer and tagged with the position of their origin. The concept behind tagged-data collection during continuous scanning originated with Legge and Hammond (1979). They described a recording system for a proton-induced X-ray emission (PIXE) system that digitized the scan and combined it with the output of multiple detectors, including a $\mathrm{Si}(\mathrm{Li})$ detector. They streamed the $x$, $y$, and energy data to magnetic tape in order of arrival time and later sorted them into a spectrum image. Application of this idea to X-ray mapping in electron beam instruments was developed by Mott et al. (Mott et al., 1995; Mott \& Friel, 1999). In this continuous scanning method, dwell times of only a few microseconds are used, and acquisition at multiple frames per second is possible. At a pixel resolution of $256 \times 256$, maps can be collected at several frames per second. Even though the data acquisition is, strictly speaking, sequential, the maps appear to have come from parallel collection and appear to "fill in" over time. In this aspect, acquisition by PTS is similar to analog "dot maps" because one can recognize specimen features within a few seconds.

The images of Figure 21 illustrate the use of shortcollection maps, displayed from PTS data, for surveying. The specimen is a multiphase ceramic superconductor containing yttrium at four concentration levels: unreacted $\mathrm{Y}_{2} \mathrm{O}_{3}$ (highest contrast in map), $\mathrm{Y}_{2} \mathrm{BaCuO}_{5}$ (211 phase), $\mathrm{YBa}_{2} \mathrm{Cu}_{3} \mathrm{O}_{7-x}$, (123 phase), and $\mathrm{BaCuO}_{2}$ (no yttrium). The operator can begin to discern these compositional differences on the basis of yttrium map intensity after only $30 \mathrm{~s}$. After $3000 \mathrm{~s}$ (50 min), enough detail is visible to recognize the four areas.

The ability to rapidly distinguish different concentration levels in the specimen arises from appropriate scaling of the display intensity and from human perception. If areas of the map containing just one count are displayed as full intensity and areas with zero counts are displayed as black, the differences are easily discerned, as in dot maps. Moreover, our visual perception tends to group similar areas together and eliminate noise. The consequence of these two effects is that areas of high concentration are readily discriminated from areas of lower concentration.

\section{Postcollection Processing-Data Mining}

Whichever spectrum-image acquisition method one uses, the result is a full X-ray spectrum at every pixel. The data in this cube can be mined for information in several ways. One can slice the cube perpendicular to the energy axis to produce maps at a given energy, or one can select regions in the spatial domain and produce selected-area spectra.

\section{Basic Data Mining}

Probably the most common use of spectrum images is the construction of X-ray maps for elements that were not known to be present in the specimen. For this, a software routine scans the spectra, finds peaks above background for all elements present, and displays maps for these elements (Figure 20), as shown schematically in Figure 22. A second data mining application is that of summing all spectra within a selected area (Mott et al., 1995) as shown in Figure 22b. Areas can be selected on the basis of contrast from any signal that can be mapped onto the cube, such as secondary electrons, backscattered electrons, specimen current, or even color from a light microscope (Friel \& Prestridge, 2002). Data from all signals are in perfect registration in the cube, so any image can be used to select areas of interest. Moreover, all the tools of image processing, editing, and comparison can be applied before choosing the area for spectrum display. One example showing the value of image 


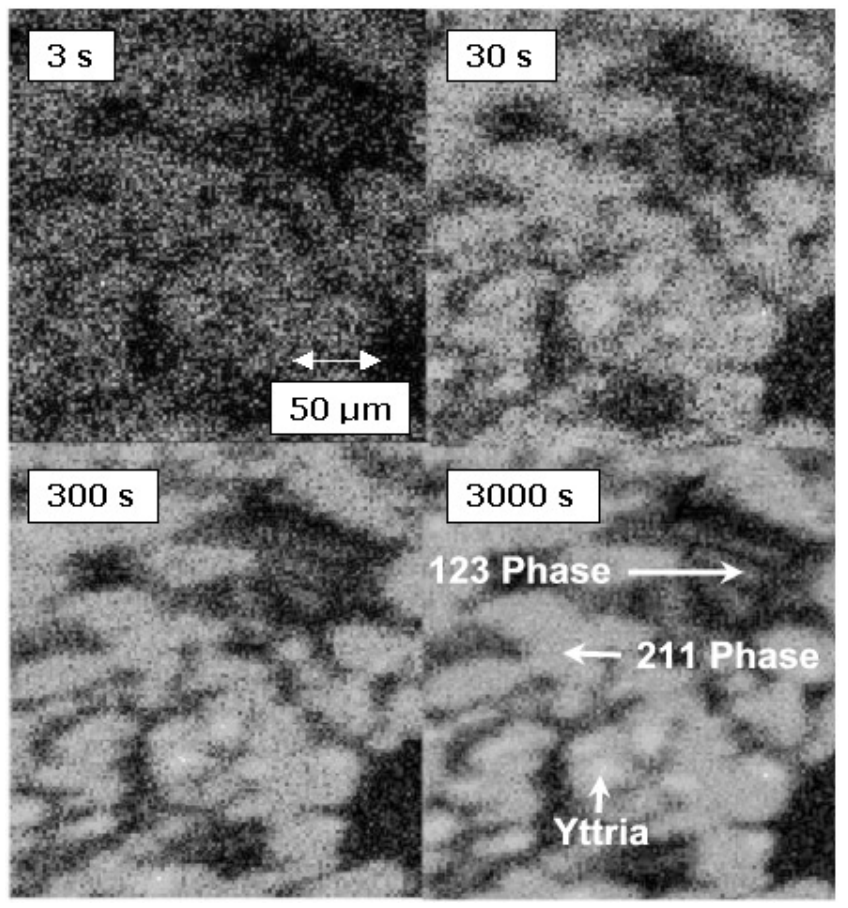

Figure 21. Position-tagged spectrometry with different collection times. Maps of yttrium in a ceramic superconductor after different acquisition times. After $300 \mathrm{~s}$ the three distinct levels of yttrium are clearly observable.
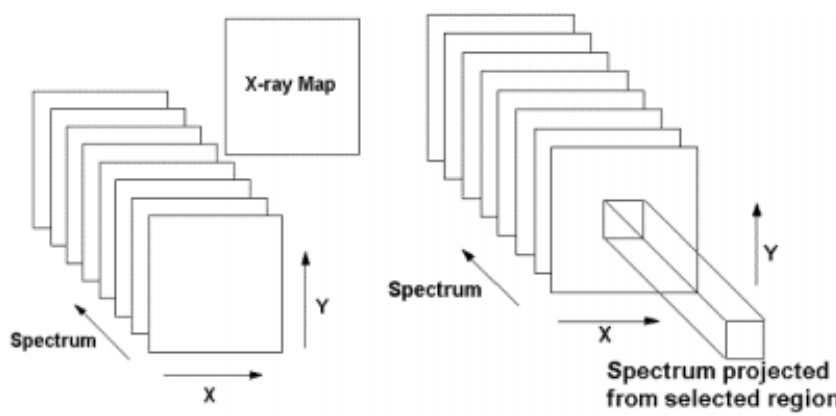

Figure 22. Schematic representation of extracting data from a spectrum image. X-ray map defined by a characteristic X-ray energy (element) by selecting a specific $x-y$ slice (left). Display of spectra from a specific area in the image by combining spectra for all pixels within the selected area (right).

processing for X-ray maps consisted of extracting and summing spectra from specific features of SiC fibers in a composite material. The mined data led to a quantitative radial oxygen profile across the SiC fibers (Friel \& Greenhut, 1997). Another example is shown in Figure 23 in which $\mathrm{X}$-ray maps reveal grain boundaries decorated with chromium carbides in a sensitized stainless steel. These maps show enrichment in $\mathrm{Cr}, \mathrm{C}$, and $\mathrm{Cl}$ (from the glyceregia etchant) along the grain boundaries. Although one could
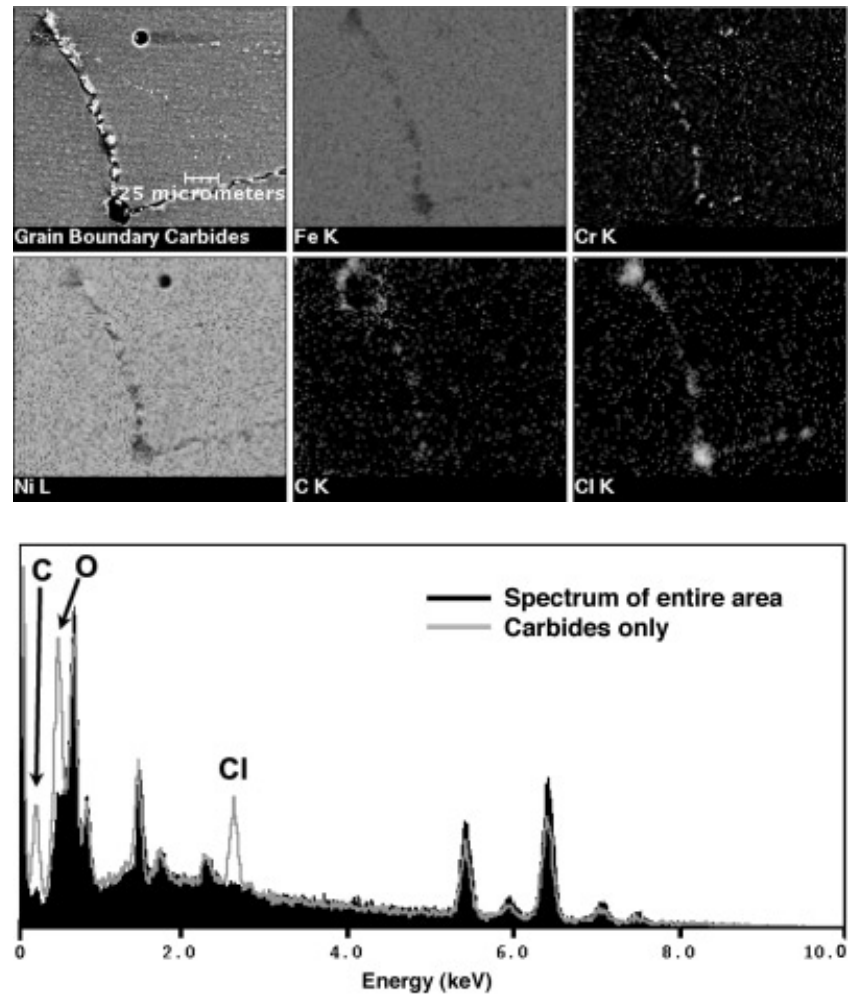

Figure 23. a: SE image and $\mathrm{X}$-ray maps of $\mathrm{Fe}, \mathrm{Cr}, \mathrm{Ni}, \mathrm{C}$, and $\mathrm{Cl}$ from a sensitized stainless steel. Chromium carbides had formed at grain boundaries as shown by the enrichment of $\mathrm{Cr}$ and $\mathrm{C}$ at the grain boundary. b: Comparison of summed spectra from only the carbide pixels (gray line) with spectra from the whole area of the specimen (solid black) shown in a. The $\mathrm{O}$ and $\mathrm{Cl}$ concentrations at the carbides are from the etchant. (Sample courtesy of George Vander Voort, Buehler, Ltd.)

analyze individual carbide precipitates in spot mode, the analysis would be made difficult by their small size and irregular surface. However, by summing the X-ray spectra from only the carbides and comparing the result with the overall X-ray spectrum, the carbides are shown to be enriched in $\mathrm{C}, \mathrm{O}$, and $\mathrm{Cl}$. The $\mathrm{O}$ and $\mathrm{Cl}$ are from the etchant (Fig. 23b).

\section{Multivariate Statistical Analysis}

There are other automatic ways of postprocessing the spectrum-image data cube. One approach to the task of automatically sorting the data has been to use multivariate statistical analysis (MSA) methods, such as principal component analysis or factor analysis (Harman, 1967; Mosteller \& Tukey, 1977). These statistical techniques seek to account for the variance in a data set. The components or factors each represent some fraction of the variance, and it is up to the analyst to decide which statistical parameters represent physical or chemical characteristics such as composition. 


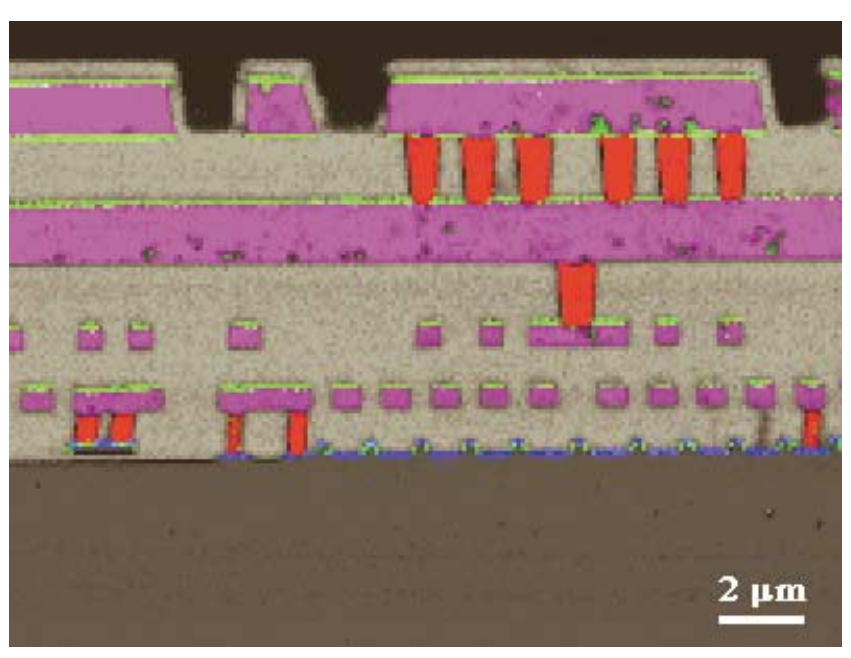

Figure 24. Component image of computer chip resulting from multivariate statistical analysis (MSA) of the spectrum image. Components are pseudocolored such that magenta $=\mathrm{Al}$, red $=\mathrm{W}$, green $=$ nitrides, and blue $=$ Co-silicide (Anderson, 2000a $)$. (Courtesy of Ian Anderson.)

Trebbia and Bonnet (1990) and Bonnet et al. (1992) have made use of these techniques to analyze EELS spectra and images. Application to X-ray mapping was described a few years later (Trebbia et al., 1995). One of the reasons for using purely statistical methods is that no a priori assumptions about the specimen are necessary. These techniques have been used for improving the signal/noise ratio for increased sensitivity in trace element analysis (Trebbia \& Bonnet, 1990), elemental segregation (Titchmarsh et al., 1995; Titchmarsh \& Dumbill, 1996), time-dependent spectroscopy (Bonnet et al., 1992), and alkali mobility in glass analysis (Jbara et al., 1995).

The most important X-ray mapping application of MSA methods is to extract from the spectrum-image data cube statistical groups that can be interpreted chemically as phases. The general application has been reviewed by Bonnet (1998), and the specific application to spectrum images has been discussed by Anderson (1998, 2000a, 2000b). Figure 24 shows the BSE image of a computer chip with superimposed component X-ray maps extracted from the spectrum image (Anderson, 2000a). The components are pseudocolored as follows: $\mathrm{Al}$, magenta; $\mathrm{W}$, red; nitrides, green; and Co silicide, blue. Note that a component can represent a phase as well as an element. It is possible to further process the extracted spectra by background subtraction and deconvolution. New component images based on the deconvoluted spectra can then be constructed.

Commercial software is available that can accomplish the selection of the principal components and provide chemical phase identification without human intervention (Kotula et al., 2003a). These authors also extended their MSA analysis (Kotula et al., 2004a) to include multivariate curve resolu-

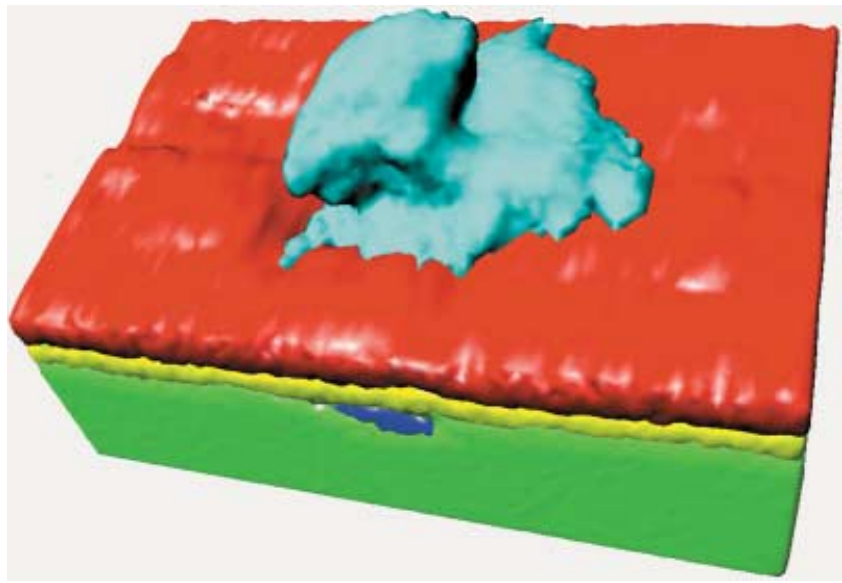

Figure 25. Three-dimensional rendering of a Cu-S corrosion product (light blue) formed at a pinhole in a Au coating on $\mathrm{Cu}$. This tomographic representation of phases can be viewed from any direction using tomographic software (Kotula et al., 2006). (Courtesy of Paul Kotula.)

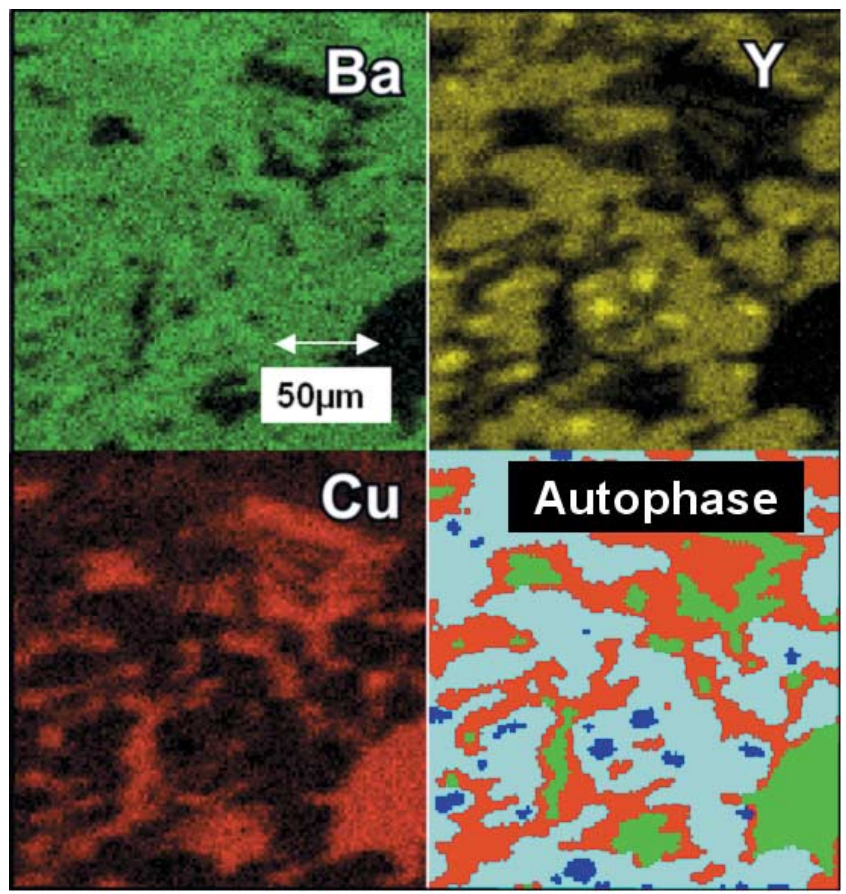

Figure 26. Phase map (lower right) extracted by the recursive pixel allocation method from $\mathrm{X}$-ray maps of $\mathrm{Ba}, \mathrm{Y}$, and $\mathrm{Cu}$. Area fractions are shown in Table 4 for the four phases: 211 phase $=$ light blue, 123 phase $=$ red, $\mathrm{Cu}$-rich phase $=$ green, and $\mathrm{Y}_{2} \mathrm{O}_{3}=$ dark blue.

tion (MCR), whereby the spectrum image is factored statistically into simpler components. A further application is the construction of three-dimensional X-ray maps using a focused ion beam (FIB) instrument to slice material from the specimen between acquisitions of spectrum images for 
Table 4. Areal Fractions Extracted for Each of the Four Phases Shown in Figure 26

\begin{tabular}{lrlrr}
\hline \multicolumn{5}{c}{ Average intensity of X rays } \\
\hline & $\mathrm{Ba}$ & $\mathrm{Y}$ & $\mathrm{Cu}$ & Area \% \\
\hline Phase 1 (light blue) & 26 & 56 & 19 & 68.54 \\
Phase 2 (red) & 28 & 24 & 48 & 18.23 \\
Phase 3 (green) & 8 & 12 & 81 & 11.11 \\
Phase 4 (dark blue) & 10 & 84 & 6 & 1.11 \\
& & & & \\
\hline
\end{tabular}

each freshly exposed surface. These tomographic spectrum images are then subjected to MSA (Kotula et al., 2003b) and MCR (Kotula et al., 2004b). After extraction, related components can be combined and rendered in three dimensions (see Fig. 25 and the article in this issue by Kotula et al.)

\section{Judgment Methods}

Mosteller and Tukey (1977), in their book on data analysis, distinguish "judgment components" from "principal components." The difference lies in whether a person's knowledge can be applied to a data set. These authors state, "When volunteered by persons of sound insight, ... [judgment components] may be better than ... [components] that mechanical processes construct on the basis of the data being analyzed" (p. 396). One implementation of a judgment method is recursive pixel allocation (RPA) (Friel \& Batcheler, 2002). In this method, the computer assigns each pixel to a phase based on similarities in X-ray intensity among elemental maps constructed from a spectrum image. In this approach, the computer examines only the data in selected maps, thus reducing the size of the working data set. However, the purpose of judgment methods is not to reduce the amount of data, but rather to affect the output. Results can be iterated by the analyst to consider different elements or different sensitivities. An example of the RPA classification method is shown in Figure 26. The figure shows $\mathrm{X}$-ray maps of $\mathrm{Ba}, \mathrm{Y}$, and $\mathrm{Cu}$ from the same sample area shown in Figure 21. Table 4 shows the data extracted for each of the four phases depicted in Figure 26, including their X-ray intensities and phase area percentage. The choice of a judgment method or a purely statistical one depends on the needs of the analyst. Nonjudgment methods such as multivariate statistical analysis produce results that are unaffected by preconceived ideas. Judgment methods perform the "autophase" function under constraints set by the user.

\section{Derived Spectra}

Although it is productive to use sophisticated data processing techniques for the spectrum-image data cube, simple functions can also yield useful information. One common operation is to sum spectra from all pixels of similar composition. This derived spectrum may be used for quantita- tive elemental analysis by phase. Another example is the maximum pixel spectrum, in which the maximum X-ray intensity value at each channel along the energy axis is plotted against energy. This operation finds regions of high concentration when they do not occupy a large volume of the specimen (Bright \& Newbury, 2004; Newbury \& Bright, 2005).

\section{CONCLUSIONS}

$\mathrm{X}$-ray mapping has been an integral part of X-ray microanalysis since the first scanning-beam X-ray microanalysis instruments were developed 50 years ago. With digital beam control and digital intensity storage, X-ray "dot maps" became digital compositional images, which are now widely used in SEMs and EPMAs. Maps from bulk specimens typically exhibit a spatial resolution of about $1 \mu \mathrm{m}$, whereas elemental detectability is in the range $0.5-1 \mathrm{wt} \%$ for WDS and $2-5 \mathrm{wt} \%$ for conventional EDS systems. In the TEM, the addition of beam scanning facilities and a high-efficiency $\mathrm{X}$-ray detector turned a high-resolution imaging microscope into a tool capable of producing high-spatial-resolution compositional maps. The extraordinary spatial resolution of $2-5 \mathrm{~nm}$ is only obtained when adequate X-ray signals can be collected from the thinnest specimens. Elemental detectability in a thin specimen X-ray map is estimated to be about $1 \mathrm{wt} \%$, depending on the specimen thickness and the instrument employed. As computer processing power and data storage became adequate, the long-desired goal of collecting and storing an entire spectrum at each pixel became a reality about a decade ago. Recently, it has become possible to use various data mining techniques to sort and analyze the resulting spectrum-image data sets. Elemental maps can be made without prior knowledge of specimen composition, and compositional information can be combined with other features in a micrograph to more fully characterize a microstructure.

\section{ACKNOWLEDGMENTS}

The authors thank those individuals who provided images or gave permission to reprint their work. Dale Newbury and Peter Duncumb read the manuscript, and their discussions and suggestions are greatly appreciated.

\section{ReFERENCES}

Allard, L.F. \& Blake, D.F. (1982). The practice of modifying an analytical electron microscope to produce clean X-ray spectra. In Microbeam Analysis-1982, Heinrich, K.F.J. (Ed.), pp. 8-20. San Francisco, CA: San Francisco Press. 
Anderhalt, R.W. \& Sandborg, A.O. (1989). Quantitative compositional mapping in a scanning electron microscope with an energy-dispersive spectrometer. In Microbeam Analysis-1989, pp. 249-253. San Francisco, CA: San Francisco Press.

Anderson, C.A. \& Hasler, M.F. (1966). Extension of electron microprobe techniques to biochemistry by the use of long wavelength X-rays. In Proceedings of the Fourth International Conference on X-ray Optics and Microanalysis, Castaing, R., Deschamps, P. \& Philibert, J. (Eds.), pp. 310-327. Paris: Hermann.

Anderson, I.M. (1998). Statistical analysis of low-voltage EDS spectrum images. In Electron Microscopy 1998, Proceedings of the 14th International Congress on Electron Microscopy, Benavides, H.A. \& Yacaman, M.J. (Eds.), pp. 357-358. Philadelphia: Institute of Physics.

Anderson, I.M. (2000a). Spectrum imaging: Microanalysis for a new millennium. Microsc Microanal 6 (Suppl. 2), 1048-1049.

Anderson, I.M. (2000b). Spectrum imaging: The future of quantitative X-ray mapping? In Microbeam Analysis 2000, pp. 437438. Philadelphia: Institute of Physics.

Armstrong, J.T. (1988). Quantitative analysis of silicate and oxide materials: Comparison of Monte Carlo, ZAF, and phi-rho-Z procedures. In Microbeam Analysis-1988, pp. 239-245. San Francisco, CA: San Francisco Press.

Bennett, J.C. \& Egerton, R.F. (1995). NiO test specimens for analytical electron microscopy: Round-robin results. Microsc Microanal 1, 143-150.

Berger, M.J. (1963). Monte Carlo calculation of the penetration and diffusion of fast charged particles. In Methods in Computational Physics, Adler, B., Fernback, S. \& Rotenberg, M. (Eds.), pp. 135-215. New York: Academic Press.

Bonnet, N. (1998). Multivariate statistical methods for the analysis of microscope image series: Applications in materials science. J Microsc 190, 2-18.

Bonnet, N., Simova, E., Lebonvallet, S. \& Kaplan, H. (1992). New applications of multivariate statistical analysis in spectroscopy and microscopy. Ultramicroscopy 40, 1-11.

Boyes, E.D. (2000). On low voltage scanning electron microscopy and chemical analysis. Microsc Microanal 6, 307-316.

Boyes, E.D. (2001). Analytical potential of EDS at low voltages. Microchem Acta 138, 225-234.

Bremier, S., Mostert, M. \& Walker, C.T. (2000). Quantitative $\mathrm{X}$-ray mapping in wavelength dispersive electron probe microanalysis. In Microbeam Analysis 2000, pp. 443-444. Philadelphia: Institute of Physics.

BRIGHT, D.S. (1995). Measurement of chemical components using scatter diagrams with principal component analysis. In Microbeam Analysis 1995, Etz, E. (Ed.), pp. 403-404. Breckenridge, CO: VCH Publishers.

Bright, D.S. \& Marinenko, R.B. (1992). Concentration histogram imaging. MSA Bull 22, 21-28.

Bright, D.S. \& Newbury, D.E. (1991). Concentration histogram imaging: A scatter diagram technique for viewing two or three related images. Anal Chem 63, 243A-250A.

Bright, D.S. \& Newbury, D.E. (2004). Maximum pixel spectrum: A new tool for detecting an drecovering rare, unanticipated features from spectrum image data cubes. J Microsc 216, 186-193.

Brundle, D., Uritsky, Y. \& Chernoff, D. (1996). Real-time simulation for X-ray microanalysis. Solid State Technol 39, 105-194.

Buskes, H.A. \& Baughman, G.D. (1988). Quantitative large-area mapping with an analytical scanning electron microscope: A study of low-level elemental segregation in continuous cast steel. In Microbeam Analysis-1988, pp. 44-46. San Francisco, CA: San Francisco Press.

Cantrill, R.K., Guiver, T.A. \& Moore, L.G. (1990). Large area $\mathrm{X}$-ray mapping in continuously cast steel sections using the CAMECA SX-50 electron probe microanalyzer. Trans Roy Microsc Soc 1, 19-22.

Castaing, R. (1951). Application of electron probes to local chemical and crystallographic analysis. Ph.D. dissertation, University of Paris.

Cazaux, J. (1996). Electron probe microanalysis of insulating materials: Quantitation problems and some possible solutions. $X$-ray Spectrom 25, 265-280.

Chambers, W.F. (1981). Digitally controlled X-ray mapping. In Microbeam Analysis-1981, Geiss, R.H. (Ed.), pp. 43-44. San Francisco, CA: San Francisco Press.

Cliff, G. \& Kenway, P.B. (1982). The effects of spherical aberration in probe-forming lenses on probe size, image resolution, and X-ray spatial resolution in scanning transmission electron microscopy. In Microbeam Analysis_-1982, Heinrich, K.F.J. (Ed.), pp. 107-110. San Francisco, CA: San Francisco Press.

Cliff, G. \& Lorimer, G.W. (1975). The quantitative analysis of thin specimens. J Microsc 103, 203-207.

Colliex, C. \& Mory, C. (1983). Quantitative aspects of scanning transmission electron microscopy. In Quantitative Electron Microscopy, Scottish Universities Summer School in Physics, Chapman, J.N. \& Craven, A.J. (Eds.), pp. 149-155. Glasgow, Scotland: Institute of Physics.

Cosslett, V.E. \& Duncumb, P. (1956). Microanalysis by a flyingspot X-ray method. Nature 177, 1172-1173.

Duncumb, P. \& Cosslett, V.E. (1957). A scanning microscope for X-ray emission pictures. In X-ray Microscopy and Microradiography, Cosslett, V.E., Engstrom, A. \& Pattee, H.H. (Eds.), pp. 374380. New York: Academic Press.

Egerton, R.F. (1996). Electron Energy-Loss Spectroscopy in the Electron Microscope. New York: Plenum Press.

Egerton, R.F. \& Cheng, S.C. (1994). Characterization of an analytical electron microscope with a $\mathrm{NiO}$ test specimen. Ultramicroscopy 55, 43-54.

Ekelund, S. \& Werlefors, T. (1976). A system for quantitative characterization of microstructures by combined image analysis and X-ray discrimination in the scanning electron microscope. In Scanning Electron Microscopy/1976, Johari, O. (Ed.), vol. 1, pp. 417-424. Chicago, IL: IIT Research Institute.

Fiori, C. (1986a). Computer-aided imaging and interpretation. In Advanced Scanning Electron Microscopy and X-ray Microanalysis, Newbury, D.E., Joy, D.C., Echlin, P., Fiori, C. \& Goldstein, J.I. (Eds.), pp. 181-241. New York: Plenum.

FIORI, C.E. (1986b). Quantitative compositional analysis of biological cryosections. In Microbeam Analysis-1986, pp. 183-186. San Francisco, CA: San Francisco Press.

Fiori, C.E., Leapman, R.D., Swyt, C.R. \& Andrews, S.B. (1988). Quantitative X-ray mapping of biological cryosections. Ultramicroscopy 24, 237-249.

Fiori, C.E., Swyt, C.R. \& Gorlen, K.E. (1984). Continuum correction of X-ray images in scanning electron column instruments. In Microbeam Analysis-1984, Romig, A.D. \& Goldstein, J.I. (Eds.), pp. 179-185. San Francisco, CA: San Francisco Press.

Fitzgerald, R., Keil, K. \& Heinrich, K.F.J. (1968). Solid-state energy dispersion spectrometer for electron-microprobe X-ray analysis. Science 159, 528-530. 
Friel, J.J. (1987). Computer-aided imaging of basaltic glass. In Microbeam Analysis-1987, pp. 325-326. San Francisco, CA: San Francisco Press.

Friel, J.J. \& BAtCheler, R. (2002). Automatic phase segmentation of spectrum images. Microsc Microanal 8 (Suppl. 2), 350-351.

Friel, J.J. \& Greenhut, V. (1997). Novel technology for X-ray mapping of ceramic microstructures. J Am Ceram Soc 80, 3205-3208.

Friel, J.J. \& Prestridge, E.B. (2002). Combined LM, SEM, and X-ray microanalysis of tint-etched cast iron. Microsc Anal 57, $5-7$.

Fritz, G.S., McCarthy, J.J. \& Lee, R.J. (1981). Interactive software for automated particulate analysis. Microbeam Analysis_-1981, pp. 57-60. San Francisco, CA: San Francisco Press.

Gao, N., Ponomarev, I.Y., Xiao, Q.F., Gibson, W.M. \& CarpenTER, D.A. (1996). Monolithic polycapillary focusing optics and their applications in microbeam X-ray fluorescence. Appl Phys Lett 69, 1529-1531.

Garratt-Reed, A.J. (1990). Applications of high-resolution X-ray mapping. In Microbeam Analysis-1990, Michael, J.R. \& Ingram, P. (Eds.), pp. 272-274. San Francisco, CA: San Francisco Press.

Goldstein, J.I., Costley, J.L., Lorimer, G.W. \& Reed, S.J.B. (1977). Quantitative X-ray analysis in the electron microscope. In Scanning Electron Microscopy/1977. Johari, O. (Ed.), vol. 1, pp. 315-324. Chicago, IL: IIT Research Institute.

Goldstein, J.I., Lyman, C.E. \& Zhang, J. (1990). In Microbeam Analysis-1990, Michael, J.R. \& Ingram, P. (Eds.), pp. 265-271. San Francisco, CA: San Francisco Press.

Goldstein, J.I., Newbury, D.E., Echlin, P., Joy, D.C., Fiori, C. \& Lifshin, E. (1981). Scanning Electron Microscopy and X-ray Microanalysis. New York: Plenum Press.

Goldstein, J.I., Newbury, D.E., Echlin, P., Joy, D.C., Lyman, C.E., Romig, A.D., Fiori, C.E. \& Lifshin, E. (1992). Scanning Electron Microscopy and X-ray Microanalysis. New York: Plenum.

Goldstein, J.I., Newbury, D.E., Joy, D.C., Lyman, C.E., Echlin, P., Lifshin, E., Sawyer, L. \& Michael, J.R. (2003). Scanning Electron Microscopy and X-ray Microanalysis. New York: Kluwer Academic/Plenum Publishers.

Goldstein, J.I., Williams, D.B. \& Cliff, G. (1986). Quantitative X-ray analysis. In Principles of Analytical Electron Microscopy, Joy, D.C., Romig, A.D. \& Goldstein, J.I. (Eds.), pp. 155-217. New York: Plenum Press.

Green, M. (1963). A Monte Carlo calculation of the spatial distribution of characteristic X-ray production in a solid target. Proc Phys Soc 82, 204-215.

Hall, T.A. (1979). Problems of the continuum-normalization method for the quantitative analysis of sections of soft tissue. In Microbeam Analysis in Biology, Lechene, C. \& Warner, R.R. (Eds.), pp. 185-208. New York: Academic Press.

Hall, T.A. \& Gupta, B.L. (1982). Quantitation for the X-ray microanalysis of cryosections. J Microsc 126, 333-345.

Harman, H.H. (1967). Modern Factor Analysis. Chicago: University of Chicago Press.

Heinrich, K.F.J. (1962a). Concentration mapping device for the scanning electron probe microanalyzer. Rev Sci Instrum 33, 884.

HeINRICH, K.F.J. (1962b). Oscilloscope readout of electron microprobe data. Adv X-ray Anal 6, 291-300.

Heinrich, K.F.J., Newbury, D.E. \& Yakowitz, H. (1976). Use of Monte Carlo Calculations in Electron Probe Microanalysis and
Scanning Electron Microscopy. Washington, DC: National Institute of Science and Technology.

Hoover, M.R., White, E.W., Lebiedzik, J. \& Johnson, G.G. (1975). Automated characterization of particulates and inclusions by computer-controlled SEM/probe. In Proceedings of the 10th Conference of the Microbeam Analysis Society, pp. 54A-54B. Bethlehem, PA: Microbeam Analysis Society.

Hovington, P., Drouin, D. \& Gauvin, R. (1997). Casino: A new Monte Carlo code for electron beam interaction, part I: Description of the program. Scanning 19, 1-14.

Hunneyball, P.D., Jacobs, M.H. \& Law, T.J. (1981). Digital X-ray mapping from thin foils. In Quantitative Microanalysis with High Spatial Resolution, Lorimer, M.J.G.W. \& Doig, P. (Eds.), pp. 195-201. London: The Metals Society.

Hunt, J.A. \& Williams, D.B. (1991). Electron energy-loss spectrumimaging. Ultramicroscopy 38, 47-73.

Ingram, P., LeFurgey, A., Davilla, S.D., Sommer, S.R., Mandel, L.J., Lieberman, M. \& Herlong, J.R. (1988). Quantitative elemental X-ray imaging of biological cryosections. In Microbeam Analysis-1988, Newbury, D.E. (Ed.), pp. 433-439. San Francisco, CA: San Francisco Press.

Jbara, O., Cazaux, J. \& Trebbia, P. (1995). Sodium diffusion in glasses during electron irradiation. J Appl Phys 78, 868-875.

Jeanguillaume, C. \& Colliex, C. (1989). Spectrum-image: The next step in EELS digital acquisition and processing. Ultramicroscopy 28, 252-257.

Joy, D.C. (1995). Monte Carlo Modeling for Electron Microscopy and Microanalysis. New York: Oxford University Press.

Kawasaki, M., Oikawa, T., Ibe, K., Park, K.-H. \& Shiojiri, M. (1998). EDS elemental mapping of a DRAM with an FE-TEM. J Elec Microsc 47, 335-343.

Keast, V.J. \& Williams, D.B. (1999). Quantitative compositional mapping of $\mathrm{Bi}$ segregation to grain boundaries in $\mathrm{Cu}$. Acta Mater 47, 3999-4008.

Kelly, J.F., Lee, R.J. \& Lentz, S. (1980). Automatic characterization of fine particles. In Scanning Electron Microscopy/1980, Johari, O. (Ed.), vol. 1, pp. 311-322. AMF O'Hare, IL: SEM Inc.

Kotula, P.G., Keenan, M.R., Grant, R.P. \& Hlava, P.F. (2004a). Multivariate statistical analysis of wavelength and energydispersive X-ray spectral images. Microsc Microanal 10 (Suppl. 2), 118-119.

Kotula, P.G., Keenan, M.R. \& Michael, J.R. (2003a). Automated analysis of SEM X-ray spectral images: A powerful new microanalysis tool. Microsc Microanal 9, 1-17.

Kotula, P.G., Keenan, M.R. \& Michael, J.R. (2003b). Tomographic spectral imaging: Comprehensive 3D X-ray microanalysis. Microsc Microanal 9 (Suppl. 2), 1004-1005.

Kotula, P.G., Keenan, M.R. \& Michael, J.R. (2004b). Tomographic spectral imaging with a dual-beam FIB/SEM: 3D microanalysis. Microsc Microanal 10 (Suppl. 2), 1132-1133.

Kotula, P.G., Keenan, M.R. \& Michael, J.R. (2006). Tomographic spectral imaging with multivariate statistical analysis: Comprehensive 3D microanalysis. Microsc Microanal 12, 36-48 (this issue).

Kuypers, S. (2001). Soft X-rays and low voltage SEM in practice. Microchem Acta 138, 235-247.

Lamvik, M.K., Ingram, P., Menon, R.G., Beese, L.S., Davilla, S.D. \& LeFurgey, A. (1989). Correction for specimen movement after acquisition of element-specific electron microprobe images. J Microsc 156, 183-190. 
Lee, R.J., Huggins, F.E. \& Huffman, G.P. (1978). Correlated Mossbauer-SEM studies of coal mineralogy. In Scanning Electron Microscopy/1978, Johari, O. (Ed.), vol. 1, pp. 561-568. AMF O'Hare, IL: SEM Inc.

LeFurgey, A., Davilla, S.D., Kopf, D.A., Sommer, J.R. \& Ingram, P. (1992). Real-time quantitative elemental analysis and mapping microchemical imaging in cell physiology. J Microsc 165, 191-223.

Legge, G.J.F. \& Hammond, I. (1979). Total quantitative recording of elemental maps and spectra with a scanning microprobe. J Microsc 117, 201-210.

LoNG, N.J. (1990). Digital X-ray mapping on an HB501 STEM: A new approach for the analysis of interfaces. Ultramicroscopy 34 , 81-83.

Lyman, C.E. (1986). Digital X-ray imaging of small particles. Ultramicroscopy 20, 119-124.

Lyman, C.E. (1992). Compositional imaging in the electron microscope: An overview. EMSA Bull 22, 1-9.

Lyman, C.E., Goldstein, J.I., Williams, D.B., Ackland, D.W., von Harrach, S., Nicholls, A.W. \& Statham, P.J. (1994). High-performance X-ray detection in a new analytical electron microscope. J Microsc 176, 85-98.

Lyman, C.E., Stenger, H.G. \& Michael, J.R. (1987). Analytical electron microscopy of a sulfur-poisoned palladium catalyst with a dedicated STEM. Ultramicroscopy 22, 129-133.

Malis, T., Cheng, S.C. \& Egerton, R.F. (1988). EELS log-ratio technique for specimen-thickness measurement in the TEM. J Electron Microsc Tech 8, 193-200.

Marinenko, R.B., Myklebust, R.L., Bright, D.B. \& Newbury, D.E. (1987). Digital compositional mapping with standard map corrections for wavelength-dispersive spectrometry defocusing. J Microsc 145, 207-223.

McСамy, C.S. (1998). On the number of discernible colors: Comment. Color Res Appl 23, 337.

McCarthy, J.J. (1979). A new technique for beam current normalization in energy dispersive analysis. In Microbeam Analysis1979, pp. 305-306. San Francisco, CA: San Francisco Press.

McCarthy, J.J. (1998). Thirty years of energy-dispersive spectrometry in microanalysis: Introduction. Microsc Microanal 4, 551.

McCarthy, J.J., Fritz, G.S. \& Lee, R.J. (1981). Acquisition, storage, and display of video and X-ray images. In Microbeam Analysis1981, pp. 30-34. San Francisco, CA: San Francisco Press.

Meeker, G.P. (1995). Constraints on formation processes of two coarse-grained calcium-aluminum-rich inclusions: A study of mantles, islands, and cores. Meteoritics 30, 71-84.

Melford, D.A. \& Duncumb, P. (1958). The metallurgical application of X-ray scanning microanalysis. Metallurgia 57, 159-161.

Michael, J.R. \& Taylor, K.A. (1988). High-resolution X-ray imaging of small copper-rich precipitates in steels. In 46th Annual Meeting of the Electron Microscopy Society of America, Bailey, G.W. (Ed.), pp. 528-529. San Francisco, CA: San Francisco Press.

Miller, P.R., Reid, A.F. \& Zuiderwyk, M.A. (1982). QEM*SEM image analysis in the determination of modal assays, mineral associations, and mineral liberation. In Proceedings-XIV International Mineral Processing Congress, Toronto, Canada, Maltby, P.D.R. (Ed.), vol. 8, p. 3. Amsterdam: Elsevier.

Mosteller, F. \& Tukey, J.W. (1977). Data Analysis and Regression. Reading, MA: Addison-Wesley.

Mott, R.B. \& Friel, J.J. (1999). Saving the photons: Mapping X-rays by position-tagged spectrometry. J Microsc 193, 2-14.
Mott, R.B., Waldman, C.G., Batcheler, R. \& Friel, J.J. (1995). Position-tagged spectrometry: A new approach for EDS spectrum imaging. In Proceedings Microscopy and Microanalysis 1995, Bailey, G.W., Ellisman, M.H., Hennigar, R.A. \& Zaluzec, N.J. (Eds.), pp. 592-593. New York: Jones and Begell.

Myklebust, R.L., Newbury, D.E. \& Marinenko, R.B. (1989). Strategies for background subtraction in electron probe microanalysis/X-ray compositional mapping. Analyt Chem 61, 1612-1618.

Newbury, D.E. (1992). Compositional imaging by electron probe microanalysis: Capabilities, limitations, opportunities. MSA Bull 22, 11-20.

Newbury, D.E. (2006). The new X-ray mapping: X-ray spectrum imaging above $100 \mathrm{kHz}$ output count rate with the silicon drift detector. Microsc Microanal 12, 26-35 (this issue).

Newbury, D.E. \& Bright, D.S. (1999). Logarithmic 3-band color encoding: Robust method for display and comparison of compositional maps in electron probe X-ray microanalysis. Microsc Microanal 5, 333-343.

Newbury, D.E. \& Bright, D.S. (2005). "Derived spectra” software tools for detecting spatial and spectral features in spectrum images. Scanning 27, 15-22.

Newbury, D.E., Fiori, C.E., Marinenko, R.B., Myklebust, R.L., Swyt, C.R. \& Bright, D.S. (1990a). Compositional mapping with the electron probe microanalyzer, part 1. Anal Chem 62, 1159A-1166A.

Newbury, D.E., Fiori, C.E., Marinenko, R.B., Myklebust, R.L., Swyt, C.R. \& BRight, D.S. (1990b). Compositional mapping with the electron probe microanalyzer, part 2. Anal Chem 62, 1245A-1254A.

Newbury, D.E. \& Joy, D.C. (1986). Modeling electron beamspecimen interactions. In Advanced Scanning Electron Microscopy and Microanalysis, Newbury, D.E., Joy, D.C., Echlin, P., Fiorim, C.E. \& Goldstein, J.I. (Eds.), pp. 3-43. New York: Plenum Press.

Newbury, D.E., Marinenko, R.B., Myklebust, R.L. \& Bright, D.S. (1991). Quantitative compositional mapping with the electron probe microanalyzer. In Electron Probe Quantitation, Heinrich, K.F.J. \& Newbury, D.E. (Eds.), pp. 335-369. New York: Plenum Press.

Nickerson, D. \& Newhall, S.M. (1943). A psychological color solid. J Opt Soc Am 33, 419-422.

Ono, Y., Nielsen, C.H., Tagata, S. \& Seo, Y. (1985). High-speed wide-area analysis by electron probe. In Microbeam Analysis1985, pp. 145-147. San Francisco, CA: San Francisco Press.

Papworth, A.J. \& Williams, D.B. (2000). Information obtained by X-ray mapping large sample areas in a FEGSTEM. In Microbeam Analysis 2000, Kona, H.I., Williams, D.B. \& Shimizu, R. (Eds.), pp. 143-144. Philadelphia: Institute of Physics.

Pointer, M.R. \& Attridge, G.G. (1998). The number of discernible colours. Color Res Appl 23, 52-54.

Reed, S.J.B. (1982). The single-scattering model and spatial resolution in X-ray analysis of thin foils. Ultramicroscopy 7, 405-409.

Reuter, K.B. \& Lyman, C.E. (1991). Improved stability of alkali metals on catalysts during analytical electron microscopy. In Proceedings of the 49th Annual Meeting of the Electron Microscopy Society of America, Bailey, G.W. \& Hall, E.L. (Eds.), pp. 10161017. San Jose, CA: San Francisco Press.

Robinson, B.W., Ware, N.G. \& Smith, D.G.W. (1998). Modern electron-microprobe trace-element analysis in mineralogy. In 
Modern Approaches to Ore and Environmental Mineralogy, Cabri, L.J. \& Vaughan, D.J. (Eds.), Short Course Series vol. 27, pp. 153-180. Ottawa: Mineralogical Association of Canada.

Russ, J.C. (1990). Computer-Assisted Microscopy. New York: Plenum Press.

Russ, J.C. (1999). The Image Processing Handbook. Boca Raton, FL: CRC Press.

Schultz, M., Rudolf, F. \& Gallitelli, M.-F. (1999). Improvement in quantitative X-ray microanalysis of biological cryosections. Microsc Microanal 5, 187-196.

Somlyo, A.P. (1984). Compositional mapping in biology: X-rays and electrons. J Ultrastruct Res 88, 135-142.

Statham, P.J. (1988). Pitfalls and advances in quantitative elemental mapping. Scanning 10, 245-252.

Statham, P.J. (1995). Quantifying benefits of resolution and count rate in EDX microanalysis. In X-ray Spectrometry in Electron Beam Instruments, Williams, D.B., Goldstein, J.I. \& Newbury, D.E. (Eds.), pp. 101-126. New York: Plenum.

Strüder, L., Meidinger, N., Stotter, D., Kemmer, J., Lechner, P., Leutenegger, P., Soltau, H., Eggert, F., Rohde, M. \& SchüleIn, T. (1999). High-resolution X-ray spectroscopy close to room temperature. Microsc Microanal 4, 622-631.

Sutfin, L.V. \& Ogilvie, R.E. (1971). Role of the gas flow proportional counter in energy dispersion analysis. In Energy Dispersion X-ray Analysis: X-ray and Electron Probe Analysis, Russ, J.C. (Ed.), pp. 197-216. Philadelphia, PA: ASTM.

Takahashi, H. \& OKumura, T. (1998). Wide area mapping of uneven specimens in an electron probe X-ray microanalyzer with wavelength dispersive spectrometers. J Electron Microsc 47, 39-46.

Titchmarsh, J.M. \& Dumbill, S. (1996). Multivariate statistical analysis of FEG-STEM EDX spectra. J Microsc 184, 195-207.

Titchmarsh, J.M., Dumbill, S. \& VAtTer, I.A. (1995). Investigation of interfacial segregation in steels using multivariate analysis of EDX spectra. In Microbeam Analysis-1995, Etz, E.S. (Ed.), pp. 259-260. New York: VCH Publishers.

Tomura, T., Okano, H., Hara, K. \& Wantanabe, T. (1968). Multistep intensity indication in scanning microanalysis. $A d v$ $X$-ray Anal 11, 316-325.

Trebbia, P. \& Bonnet, N. (1990). EELS elemental mapping with unconventional methods I. Theoretical basis: Image analysis with multivariate statistics and entropy concepts. Ultramicroscopy 34, 165-178.

Trebbia, P., Wulveryck, J.M. \& Bonnet, N. (1995). Progress in quantitative elemental mapping by X-ray imaging. Microbeam Anal 4, 85-102.

Tsuneta, R., Koguchi, M., Nakamura, K. \& Nishida, A. (2002). A specimen-drift-free EDX mapping system in a STEM for observing two-dimensional profiles of low dose elements in fine semiconductor devices. J Electron Microsc 51, 167-171.

Vale, S.H. (1987). Drift corrected X-ray mapping in the analytical electron microscope. In EMAG-1987: Analytical Electron Microscopy, Lorimer, G.W. (Ed.), pp. 15-18. London: Institute of Metals.

Wachtman, J.B. (1993). Characterization of Materials. Stoneham, MA: Butterworth-Heinemann.

Warley, A. (1997). X-ray Microanalysis for Biologists. London: Portland Press.

Watanabe, M., Carpenter, D.T., Barmak, K. \& Williams, D.B. (1997). Quantitative X-ray mapping with high resolution. In Electron Microscopy and Analysis 1997, pp. 295-298. Bristol: Institute of Physics.

Watanabe, M., Horita, Z. \& Nemoto, M. (1996). Absorption correction and thickness determination using zeta factor in quantitative X-ray microanalysis. Ultramicroscopy $\mathbf{6 5}$, 187-198.

Watanabe, M. \& Williams, D.B. (1999). Atomic-level detection by X-ray microanalysis in the analytical electron microscope. Ultramicroscopy 78, 89-101.

Watanabe, M., Williams, D.B. \& Tomokiyo, Y. (2003). Comparison of detectability limits for elemental mapping by EF-TEM and STEM-XEDS. Micron 34, 173-183.

Williams, D.B. \& Carter, C.B. (1996). Transmission Electron Microscopy. New York: Plenum Press.

Williams, D.B. \& Goldstein, J.I. (1981). Artifacts encountered in energy dispersive X-ray spectrometry in the analytical electron microscope. In Energy Dispersive X-ray Spectrometry, Heinrich, K.F.J., Newbury, D.E., Myklebust, R.L. \& Fiori, C.E. (Eds.). NBS Special Publication 604, pp. 341-349. Washington, DC: National Bureau of Standards.

Williams, D.B., Goldstein, J.I. \& Newbury, D.E., Eds. (1995). $X$-ray Spectrometry in Electron Beam Instruments. New York: Plenum Press.

Williams, D.B., Papworth, A.J. \& Watanabe, M. (2002). High resolution X-ray mapping in the STEM. J Electron Microsc 51(Suppl.), S113-S126.

Wong, J.G., Wilkinson, L.E., Chen, S.W., Izutsu, K.T., Johnson, D.E. \& Cantino, M.E. (1989). Quantitative elemental imaging in the analytical electron microscope with biological applications. Scanning 11, 12-19.

Ziebold, T.O. (1967). Precision and sensitivity in electron microprobe analysis. Anal Chem 39, 858-861.

Zierold, K., Tardent, P. \& Burakov, S.V. (1991). Elemental mapping of cryosections from cnidarian nematocytes. Scan Microsc 5, 439-444. 